\title{
La Universidad española en un mundo globalizado: los recursos
}

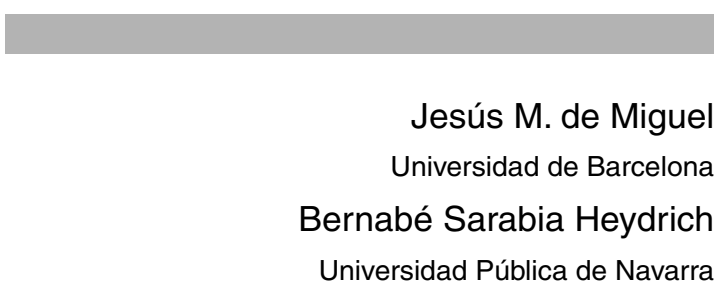

RESUMEN

Este artículo constituye una primera investigación —en el siglo xxI- sobre la Universidad en España en comparación con los sistemas de educación postsecundaria de los países del mundo. Analiza los recursos universitarios y su distribución por países. Presenta primero los datos internacionales sobre niveles generales de escolarización, para centrarse en la "educación terciaria» (postsecundaria). Se presenta la evolución en las últimas tres décadas, así como las tasas actuales de estudiantes. Analiza los recursos económicos en el contexto de las desigualdades existentes en los países del mundo, además de la proporción del PNB y el gasto por estudiante. Diferencia el sector público y el privado, diversos niveles de la Administración y los sistemas de ayuda económica a estudiantes. Entre los recursos se analizan en detalle los relativos a investigación y desarrollo (I+D) tanto en capital humano como en presupuesto. El artículo finaliza con un detalle de los datos sobre bibliotecas universitarias en el contexto del conjunto de las bibliotecas de cada país. El artículo demuestra las diferencias más importantes de la Universidad española en comparación con los demás países de la Unión Europea. Se utilizan los mejores datos de la UNESCO, la OCDE, el Banco Mundial y las Naciones Unidas. Este artículo es parte de una línea de investigación que se desarrolla en colaboración con varios centros: Universidad de Barcelona, Universidad Pública de Navarra, Georgetown University, University of Pennsylvania y el Comité de Ciencias Sociales del European Cooperation in the Field of Scientific and Technical Research (de la Comisión Europea, Bruselas).

Palabras clave: Universidad, Política Educativa, Financiación, Globalización. 
Varios estudios internacionales analizan las características esenciales del sistema educativo español en relación con la estructura del mercado laboral ${ }^{1}$. Sus conclusiones se resumen en siete características del sistema educativo español, cuando se compara con la Unión Europea y otros países avanzados: 1) España es un caso de la existencia de diferencias generacionales en educación. Tradicionalmente ha tenido un nivel escaso de inversión pública en educación, que actualmente se refleja en bajos niveles de educación entre la población adulta. Los cambios producidos en financiación y recursos crean el contraste de que la población madura tiene un nivel educativo formal escaso, mientras que la población joven está proporcionalmente más en el sector educativo que en otros países desarrollados. 2) Las diferencias en el gasto en educación con esos países, que eran considerables hace unas décadas, se van acortando, pero el gasto del sector público en educación es todavía significativamente menor que en otros países industrializados. 3) Parte de los problemas de recursos derivan del incremento súbito del número de estudiantes en las últimas décadas del siglo xx. España es actualmente uno de los países del mundo con una proporción mayor de jóvenes estudiando. Este hecho se agudiza, en parte, por las altas tasas de desempleo juvenil. 4) El proceso de crecimiento se ha potenciado con la feminización súbita del sector educativo, más evidente aún en la educación terciaria (universitaria), donde las mujeres son ya mayoría. 5) Un problema peculiar de España es la ineficacia del sistema educativo para ofrecer los conocimientos y destrezas requeridos por las empresas. La formación profesional es limitada, pero las empresas confían más en la educación externa que en la formación en el trabajo. La formación de los/as trabajadores por parte de las empresas está por debajo del resto de los países de la Unión Europea. 6) Las diferencias en la tasa de desempleo según el nivel educativo son pequeñas, pero su evolución es consistente, mostrando que las personas con más educación formal experimentan niveles más bajos de desempleo. Las personas con educación terciaria tienen tasas más altas de empleo. La excepción es la población con educación secundaria, que experimenta las tasas más altas de desempleo y está sufriendo la crisis de un modo más profundo. 7) El nivel de eficacia del sistema educativo es menor del esperado. España destaca por tener muchos estudiantes matriculados, pero los niveles de graduación son menores que en otros países, debido a una tasa elevada de suspensos, retraso en la realización de la carrera y abandono de los estudios iniciados ${ }^{2}$.

\footnotetext{
1 Por ejemplo, European Commission (1994). Para una comparación de calidad de vida, véase el informe del United Nations Development Programme (UNDP) titulado Human Development Report 2002: Deepening Democracy in a Fragmented World (2002). Conviene ver también el documento marco del Ministerio de Educación, Cultura y Deporte sobre La integración del sistema universitario español en el Espacio Europeo de Enseñanza Superior (febrero 2003).
}

2 De los mismos autores —De Miguel y Sarabia - puede verse «La Universidad española en un mundo globalizado: Los resultados" (2002). 


\section{NIVELES DE ESCOLARIZACIÓN}

La situación educativa en España es contradictoria. Todavía pesan las décadas de escolaridad incompleta, que se reflejan en una población madura con niveles de educación bajos. Ello se debe a la escasez secular de inversión del sector público en educación. Son, además, generaciones que han experimentado una guerra civil (1936-1939) y cuatro décadas de dictadura (1939-1975). España está cambiando a gran velocidad, siendo actualmente uno de los países con más jóvenes matriculados en el sistema educativo. Pero la eficacia del sistema educativo es escasa (tasas bajas de graduación), un hecho en parte explicable porque el gasto del sector público en educación es más bajo de lo esperable si se tiene en cuenta el nivel de desarrollo del país. Se ha producido un proceso de feminización de la educación, que se observa de forma más evidente en el nivel universitario, donde las mujeres son ya mayoría (53\%). Pero ese proceso no responde a una planificación ni a una política coherente del sector público. El aumento de estudiantes de todo tipo $-\mathrm{y}$ al mismo tiempo la contención del gasto- explica la eficacia baja del sistema educativo. Niveles altos de desempleo juvenil llevan a la juventud a seguir estudiando, especialmente a las mujeres. La mujer tiene una tasa de desempleo mucho mayor que el varón. Además, la juventud (especialmente mujeres) se resiste a ser población no-activa. Los jóvenes permanecen dependientes de la generación de los padres más años que en otros países desarrollados, pero no se dedican a labores domésticas. Como además muchos/as jóvenes están realizando estudios terciarios, el $83 \%$ sin beca, ello contribuye a que la tasa de natalidad española sea una de las más bajas del mundo.

España está consiguiendo acercarse cada vez más a los niveles educativos de la Unión Europea (y de otros países avanzados), pero en su nivel de calidad todavía permanece algo por debajo de lo esperable. En ese contexto, las tasas de educación terciaria españolas son altas, y los niveles de desempleo de la población con educación terciaria dentro del país son los más bajos. Expertos internacionales sugieren que la solución está en un incremento sensible de la inversión del Estado en educación, y también de las empresas (European Commission, 1994: 59). La contención demográfica al inicio del siglo XXI permite redistribuir recursos públicos con mayor rentabilidad, y reorganizar el sistema educativo global.

Los mejores datos internacionales sobre educación son los de UNESCO y OCDE. UNESCO publica anualmente el anuario Statistical Yearbook, con datos oficiales de cada país sobre los diversos niveles educativos (incluyendo la Universidad). Contiene datos de 219 Estados miembros de las Naciones Unidas, la cuarta parte de ellos clasificados como «países desarrollados», entre ellos España. Los datos de UNESCO son los de referencia oficial en el mundo y, aunque la comparación de estadísticas estatales es complicada, sigue siendo 
la mejor fuente de información que existe. A su vez, los países desarrollados (avanzados) publican estadísticas más detalladas sobre algunos aspectos de la educación a través de la OCDE, que elabora tablas con un mayor nivel analítico en su anuario Education At a Glance. Ambas publicaciones aparecen en París, en ediciones plurilingües. Los datos de OCDE complementan los de UNESCO, presentando estadísticas detalladas pero que son solamente comparables entre los países más desarrollados. Otros datos económicos y de educación provienen del Banco Mundial, y pueden ser consultados a través de la red o en su biblioteca en Washington $\mathrm{DC}^{3}$. El problema es que los países pobres no sólo se caracterizan por tener recursos públicos escasos en educación, sino también pocas estadísticas, con datos que son escasamente fiables. Eso hace más difícil la comparación internacional con los países menos desarrollados. La situación de España debe analizarse en un contexto mundial, comparándola especialmente con los países desarrollados, y sobre todo con la Unión Europea. Es lo que actualmente se conoce como «espacio» europeo de educación terciaria. El modelo europeo no es convergente; en realidad, no existe un modelo europeo único. Pero los indicadores españoles deben compararse con los conseguidos por los demás países de la Unión Europea.

El progreso educativo en la segunda parte del siglo xx es evidente. En especial, la educación terciaria («superior» o universitaria) ha experimentado un avance considerable, sobre todo en los países industrializados. En ese contexto positivo, España es una experiencia de éxito considerable, con un nivel de progreso acelerado que se encuentra entre los más importantes del mundo. Tan sólo Japón tiene una experiencia de éxito similar, aunque todavía no ha logrado incorporar a la mujer al sistema educativo en la misma proporción. En el contexto mundial, Estados Unidos sigue siendo el primer país, con proporciones altas de población con educación terciaria. Australia y Canadá muestran también una situación favorable. Les siguen los países europeos más centrales: Alemania, Francia y Reino Unido.

A nivel individual o generacional, la educación constituye un proceso de acumulación. Cada ciclo educativo depende del anterior, que hay que superar para poder iniciar el siguiente. Las cohortes van disminuyendo. La situación actual depende de la conducta de generaciones anteriores, así como de las inversiones del Estado en el sector educativo en momentos distintos de la historia. El sistema educativo puede ser visto también como un sistema de selección de las personas más productivas. Es un sistema de ciclos —primaria, secundaria, terciaria - en que cada vez quedan menos personas de una cohorte determinada. La proporción de población en cada uno de esos tres ciclos conforma una estructura que condiciona el desarrollo de un país.

3 El informe Human Development Report 2002 de las Naciones Unidas (concretamente del United Nations Development Programme, UNDP) presenta datos excelentes sobre 173 países del mundo. 
La raíz de todo es la no-educación, es decir, la tasa de analfabetismo, que es todavía un indicador esencial en el mundo, aunque ya no tanto en España. En la tabla 1 se presenta la evolución de las tasas de analfabetismo entre los años 1970 y 2000 . Al inicio del siglo XXI, todavía una de cada cinco personas adultas en el mundo es analfabeta: $26 \%$ de mujeres y

TABLA 1

Evolución de las tasas de analfabetismo, 1970-2000

(En porcentajes)

\begin{tabular}{|c|c|c|c|c|c|}
\hline Niveles de desarrollo & 1970 & 1980 & 1990 & $\frac{\text { Años }}{2000(d)}$ & $\begin{array}{r}\text { Reducción } \\
\text { del analfabetismo } \\
\text { (tasa en el año } 2000 \\
\text { si } 1970 \text { es igual a 100) }\end{array}$ \\
\hline Total del mundo & 37 & 31 & 25 & $21(e)$ & 56 \\
\hline $\mathrm{N}$ (en millones) & 854 & 880 & 882 & 876 & 103 \\
\hline Países desarrollados: & 6 & 3 & 2 & 1 & 19 \\
\hline Europa & 7 & 4 & 2 & 1 & 19 \\
\hline Países en desarrollo: & 52 & 42 & 33 & 26 & 51 \\
\hline Latinoamérica (a) & 26 & 20 & 15 & 12 & 45 \\
\hline Estados árabes & 71 & 60 & 49 & 39 & 55 \\
\hline Asia oriental (b) & 44 & 31 & 20 & 13 & 30 \\
\hline Asia meridional & 68 & 61 & 53 & 46 & 67 \\
\hline África subsahariana & 72 & 62 & 51 & 40 & 55 \\
\hline Países menos desarrollados (c): & 73 & 66 & 58 & 49 & 67 \\
\hline España (f) & 7 & 6 & 4 & 2 & 29 \\
\hline
\end{tabular}

NOTAS:

Es la proporción de la población analfabeta de 15 y más años.

(a) Incluye Caribe.

(b) Asia del Este y Oceanía.

(c) Están incluidos en los «países en vías de desarrollo».

(d) El dato del año 2000 es una estimación basada en los datos de 1998, realizada por la UNESCO.

(e) Supone $26 \%$ mujeres y $15 \%$ varones.

(f) España está incluida también en «países desarrollados».

FUENTES:

UNESCO, Statistical Yearbook 1999 (París: Unesco Publishing \& Bernan Press, 1999), II, pp. 7-8 y 50. La clasificación de países por niveles de desarrollo aparece en la p. I-10. En total son 219 países, 53 de ellos desarrollados y 166 en desarrollo. Latinoamérica son 46 países; Estados árabes, 21; Asia oriental y Oceanía, 35; Asia meridional, 9, y África subsahariana, 51. Hay otros ocho países en desarrollo. Hay cuatro países que aparecen en dos grupos al mismo tiempo (en Estados árabes y en África subsahariana), que son: Djibouti, Mauritania, Somalia y Sudán. Los 166 países en desarrollo incluyen 49 que se consideran como «menos desarrollados» (30\% de los países en desarrollo, o bien $22 \%$ del total mundial).

http://unescostat.unesco.org/en/stats/stats0.htm (consulta realizada 30 mayo 2001).

www.ine.es/tempus/cgi-bin/itie (consultado 1 junio 2001) 
$15 \%$ de varones (las mujeres son analfabetas $73 \%$ más que los varones). Una de cada cuatro mujeres es una proporción más alta de lo esperable, teniendo en cuenta el nivel de avance tecnológico logrado en el mundo. El progreso educativo realizado en las tres últimas décadas es considerable: la proporción de analfabetismo en el mundo ha descendido del 37 al $21 \%$. En porcentajes la reducción es casi a la mitad, pero en números absolutos la población analfabeta entre 1970 y 2000 aumenta: pasa de 854 a 876 millones. Es un aumento de apenas un $2,6 \%$, pero es significativo que la cantidad de población analfabeta todavía crezca, aunque la tendencia en la última década sea por fin a decrecer ligeramente.

El analfabetismo correlaciona estrechamente con la riqueza del país. Los 49 países menos desarrollados del mundo tienen una tasa de analfabetismo de aproximadamente la mitad de la población (49\%). Muchas de esas personas son mujeres. Entre los países en desarrollo las diferencias son grandes: África (subsahariana) tiene todavía un 40\% de analfabetismo, similar al $39 \%$ de los Estados árabes, que, a pesar de su desarrollo económico relativo, muestran muchas diferencias por género, y Asia meridional, con una tasa incluso mayor (46\%), en parte por la misma razón. Todo sugiere que las desigualdades por género —que varían según países y religiones — tienen una influencia fundamental en el progreso educativo, junto a las inversiones del sector público.

En cuanto a la no-educación, el progreso máximo se observa en los países desarrollados (Europa) y también en Asia oriental. El cambio es mínimo en los países subdesarrollados y en Asia meridional, en donde la situación es la peor, y no parece estar mejorando mucho. El continente asiático incluye pautas diferentes, con el máximo de éxito en la parte oriental y el retraso mayor en el Sur. La situación de Asia, que parece polarizarse, es importante dado que afecta a un volumen enorme de población. Seis de los países más poblados del mundo están en Asia: China el primero, con 1.244 millones de habitantes; India el segundo, con 955 millones. En el puesto cuarto se encuentra Indonesia, con 200 millones. Pakistán es el séptimo país en población, con 138 millones; seguido de Japón (el octavo), con 126 millones, y Bangladesh (el noveno), con 122 millones. El hecho de que las pautas en Asia se polaricen es un indicador de posibles conflictos futuros en la región.

Frente a un $49 \%$ de población analfabeta en los países menos desarrollados, Europa exhibe una tasa del 1\%. España tiene aproximadamente el doble de proporción de analfabetismo de lo esperado según su situación en la Unión Europea; pero el progreso en los últimos años está siendo rápido. En 1980, España tenía todavía un 6\% de analfabetos/as - la mayor parte personas mayores-, pero en la actualidad la cifra es tres veces menor. Las diferencias generacionales en educación son considerables. El analfabetismo afecta fundamentalmente a ancianas/os, mujeres, personas desempleadas e inactivas económi- 
camente. Bastará con dejar pasar unos años para que la situación general mejore en España con respecto a este indicador. El analfabetismo ya no es un problema en Europa, ni en los países desarrollados, pero condiciona históricamente los niveles de escolarización subsecuentes, hasta llegar a la educación terciaria.

La educación terciaria (enseñanza «superior» o universitaria) es un indicador cada vez más revelador del desarrollo de un país. Antiguamente era la educación secundaria; actualmente, la educación terciaria es el indicador mejor para entender las diferencias entre países. En ese contexto, España aparece situada favorablemente. En la tabla 2 se presentan

Tasas de escolarización según niveles, circa 1997

\begin{tabular}{lcccc} 
& \multicolumn{2}{c}{ Niveles de educación } \\
\cline { 2 - 4 } Niveles de desarrollo & Primaria & Secundaria & Terciaria (d) & Todos los niveles \\
\hline Total del mundo & 102 & 60 & 17 & 63 \\
Países desarrollados: & & & 52 & 86 \\
Europa & 103 & 100 & 43 & 83 \\
Países en desarrollo: & 105 & 99 & 10 & 59 \\
Latinoamérica (a) & 102 & 52 & 19 & 73 \\
Estados árabes & 114 & 62 & 15 & 58 \\
Asia oriental (b) & 85 & 57 & 7 & 68 \\
Asia meridional & 118 & 66 & 4 & 52 \\
África subsahariana & 95 & 45 & 26 & 33 \\
Países menos desarrollados (c): & 77 & 19 & 36 \\
España (1996) & 72 & 120 & 51 & 92
\end{tabular}

NOTAS:

Las tasas se calculan con el número estudiantes (de cualquier edad) por la población de las edades oficialmente en ese nivel de educación, en cada país. La educación terciaria tiene en cuenta cinco años después del final de la educación secundaria. Se expresan en porcentajes, y pueden superar el $100 \%$ en casos de matriculación temprana y repetidores.

(a) Incluye Caribe.

(b) Asia del Este y Oceanía.

(c) Son 48 países que están incluidos en los 170 «países en vías de desarrollo».

(d) «Educación terciaria» es lo que se conoce como educación superior, que incluye universidades y educación superior nouniversitaria.

FUENTE:

UNESCO, Statistical Yearbook 1999 (París: Unesco Publishing \& Bernan Press, 1999), II, pp. 18-20. Datos para España en II, p. 355 
las tasas de escolarización en el mundo, según niveles: educación primaria, secundaria y terciaria. Las tasas se calculan como porcentaje de jóvenes de las edades típicas de cada nivel que están matriculados/as efectivamente. La educación primaria universal se ha conseguido ya en casi todo el mundo: apenas hay diferencias entre países desarrollados y países en desarrollo. Únicamente África y los países menos desarrollados mantienen todavía un nivel de escolarización primaria que oscila entre el 70 y el $80 \%$ de esas generaciones infantiles. La educación secundaria es obligatoria (y por lo tanto universal) en el mundo desarrollado, pero presenta diferencias en el resto de los países. Alcanza a la mitad de la población en las cohortes respectivas de los países en desarrollo, pero sólo a una de cada cinco personas en los países menos desarrollados.

Las diferencias máximas se observan en educación terciaria (universitaria). En los países desarrollados la mitad de las cohortes respectivas de jóvenes están ya en educación terciaria (52\%). Estos países presentan una tendencia hacia la universalización de la educación terciaria, con tasas que empiezan ya a superar el $75 \%$ de jóvenes de las edades respectivas en algunos países. En cambio, en los países en vías de desarrollo el modelo de educación terciaria es elitista, matriculando solamente a una de cada diez personas jóvenes. El conjunto de los 49 países menos desarrollados del mundo tienen un sistema educativo en que solamente el $3 \%$ de los/as jóvenes (en edad universitaria) están realmente matriculados en educación terciaria. Se observan pautas regionales: Latinoamérica presta bastante atención a educación y, sin embargo, en África es escasa. Los países pobres -endeudados internacionalmente- a menudo no tienen más remedio que disminuir sus presupuestos públicos en educación.

España mantiene unas tasas similares a la media del mundo desarrollado. Las tasas de población escolarizada en España son altas: escolarización universal en educación primaria y secundaria, y alcanza al $51 \%$ de los jóvenes de las edades respectivas en educación terciaria. Ha superado ya el listón simbólico de la mitad de la población en 1997, y camina hacia una proporción que podría alcanzar el 75\% en una o dos décadas. El mundo desarrollado consiguió hace tiempo la universalización de la educación primaria, haciéndola obligatoria. Posteriormente logró también la universalización de la educación secundaria. En estos momentos el mundo desarrollado camina hacia la universalización de la educación terciaria, que no va a considerarse «obligatoria» pero que de facto incluye a más de las tres cuartas partes de cada cohorte de jóvenes. España es un caso ejemplar en esta pauta, con una escolarización obligatoria universal, con una educación secundaria bastante extendida y que todavía puede expandir bastante la universitaria, a pesar de que ya tiene una tasa media de las más altas de la Unión Europea. Según estas cifras, la situación educativa de España es ejemplar, con tasas más altas de lo esperable según su nivel de desarrollo económico. Hay que tener en cuenta, además, que esos niveles altos se consi- 
guen con recursos públicos escasos, lo que es un mérito. A principios del siglo xxı la formación educativa se considera como un esfuerzo a realizar, valorado positivamente.

La distribución de la educación terciaria discrimina el desarrollo de los países, y es especialmente numerosa en el caso español. La tabla 3 presenta datos de la educación de la población total y de la población activa por niveles (educación primaria, secundaria, terciaria) para tres grupos de países industrializados miembros de la OCDE. En el primer grupo están tres países desarrollados, ordenados por renta per capita (RPC): Japón, Estados Unidos y Australia. Luego se incluyen tres países europeos centrales: Alemania, Francia y Reino Unido. Abajo se incluyen tres países del sur de Europa: Italia, España y Portugal. En cada grupo los países están ordenados por nivel de riqueza (RPC). La tabla mide el nivel de educación actual de la población madura, es decir, de 25 a 64 años de edad. Compara la población total con la población activa de las mismas edades. El nivel de desarrollo explica la proporción de población con pocos estudios -educación primaria o menos-, que varía desde el $2 \%$ en Alemania al $68 \%$ en Portugal. En ese contexto, España tiene una proporción muy alta (44\%) de población de 25 a 64 años que apenas tiene estudios. Los mayores de 65 años tienen menos educación. Ello es consecuencia de una situación histórica y estructural que cambia lentamente pues se refiere a población adulta, seguramente la de más edad. Todavía en el mundo desarrollado la proporción de personas adultas con poca educación formal es un factor que discrimina, y que diferencia niveles globales de desarroIlo, sobre todo en el mundo laboral. La variabilidad en la proporción de población con estudios secundarios (superiores) es también grande y significativa. Alemania tiene seis veces más población con educación secundaria que Portugal (61\% versus $11 \%$ ). España tiene una proporción baja (14\%), lo que representa 2,5 veces menos que Italia en el mismo segmento de desarrollo. En los países más desarrollados - hay excepciones como Australia o Francia - la mitad de la población adulta tiene estudios secundarios (superiores) terminados. En el contexto europeo, los países meridionales presentan todavía una situación bastante inferior.

Las diferencias en educación terciaria no son tan grandes, pero presentan pautas sistemáticas. Los países mas ricos están en torno al 30\% de población con estudios terciarios; los países europeos centrales, alrededor del 20\%; y los meridionales, el 10\%. España destaca con una proporción el doble de alta de lo esperado de población con estudios terciarios (20\%). España es un caso atípico, con desigualdades extremas: demasiada población sin apenas estudios (una de las proporciones más altas), incluso pocas personas con enseñanza secundaria (uno de los porcentajes más bajos), pero con una proporción de población con estudios universitarios el doble de lo esperable para su nivel de desarrollo. El modelo español es, pues, dicotómico, lo que supone conflictos internos en el mercado de trabajo. Es sorprendente que en España una de cada cinco personas adultas tenga estu- 


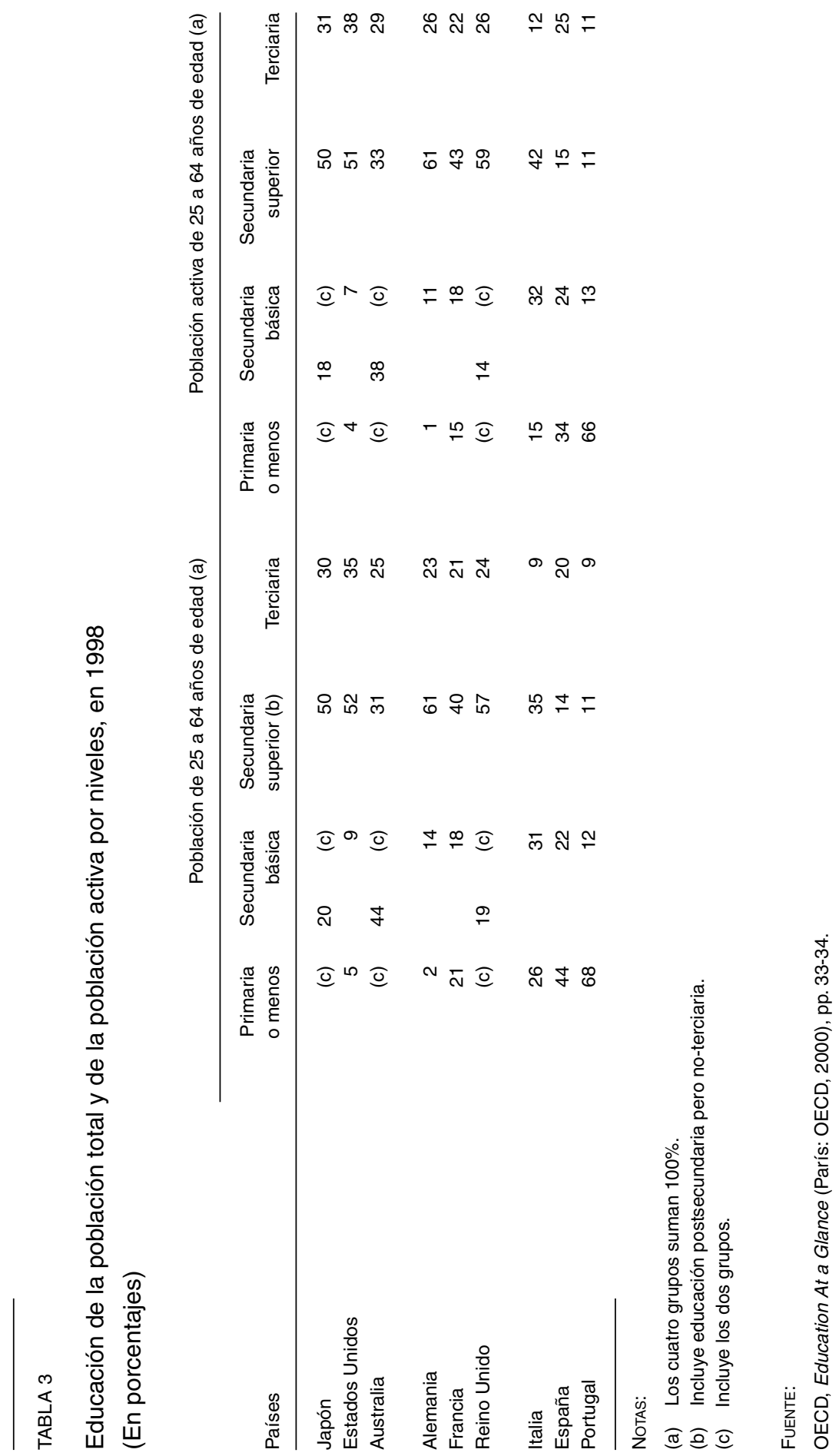


dios terciarios cuando en la región es una de cada diez. La situación de la educación terciaria en España está prácticamente a la altura de los países europeos centrales: Alemania, Francia y Reino Unido.

Si en vez de analizar la población adulta global — de 25 a 64 años— se mide la distribución educativa de la población económicamente activa (que incluye la población desempleada), las proporciones casi no varían. Apenas hay diferencias en la composición por niveles educativos de la población total y la activa. Se observa que las personas con estudios escasos (primaria o menos) tienden a estar menos activas en el mercado de trabajo. Eso ocurre en todos los países. La población adulta sin estudios en España asciende a un 44\%; en su población activa representa solamente el 34\%. No hay apenas diferencias en lo relativo a educación secundaria (superior): las proporciones de la población general y la población activa son similares. Las diferencias son también pequeñas en educación terciaria, aunque siempre hay una proporción mayor de población activa con estudios terciarios que en el total de la población adulta. Esta pauta es más exagerada en España, donde las personas con educación terciaria pasan de ser una de cada cinco en la población general a una de cada cuatro en la población activa. En España - más que en otros países- la educación terciaria diferencia a las personas. La población con estudios terciarios en España es proporcionalmente más activa en el mercado laboral. Además, se sabe que su desempleo es menor. El tener estudios universitarios en España es una característica discriminante que alcanza a más población de la esperada. De ahí la importancia que se otorga a la educación terciaria en el país.

La tabla 4 presenta datos más concretos de población escolarizada como proporción de la población total a determinadas edades. Los países desarrollados del mundo han conseguido que la mayor parte de sus teenagers estén estudiando: alcanzando el $76 \%$ de jóvenes matriculados entre 15 y 19 años de edad. En su segunda década de vida (20 a 29 años de edad) solamente una de cada cinco personas está estudiando. Se entiende que la proporción es mayor en la primera parte y mucho menor en la segunda parte de ese grupo de edad de 20 a 29 años. En la tercera década de vida la proporción baja al 4\%, y posteriormente es el $1 \%$ de la población. No hay grandes diferencias en la proporción de jóvenes que están estudiando entre 15 y 19 años de edad. Todos los países industrializados consiguen que estudien entre un 70 y un $88 \%$ de esas cinco cohortes. Hay más diferencias según aumenta la edad de las personas. En la segunda década de vida (20 a 29 años de edad) las diferencias entre países oscilan entre el 17 y el $27 \%$. En edades más maduras, Australia y Reino Unido presentan una pauta con bastantes estudiantes; pero en el resto de países la proporción apenas varía.

España mantiene una tasa estudiantil media a niveles de secundaria superior (15 a 19 años), con un $76 \%$ de la población de esas edades estudiando, que es exactamente la me- 
TABLA 4

Población escolarizada como proporción de la población total a determinadas edades, en 1998 (En porcentajes)

\begin{tabular}{|c|c|c|c|c|c|}
\hline \multirow[b]{2}{*}{ Países } & \multicolumn{4}{|c|}{$\begin{array}{l}\text { Estudiantes de esa edad del total } \\
\text { de población de la misma edad (en años) }\end{array}$} & \multirow{2}{*}{$\begin{array}{l}\text { Proporción de jóvenes } \\
\text { de } 20 \text { años de edad } \\
\text { en educación terciaria }\end{array}$} \\
\hline & 15 a 19 & 20 a 29 & 30 a 39 & $\begin{array}{r}40 \mathrm{y} \\
\text { más años }\end{array}$ & \\
\hline Media países OCDE & 76 & 20 & 4,4 & 1,2 & 28 \\
\hline Japón & $\ldots$ & $\ldots$ & $\ldots$ & $\ldots$ & $\ldots$ \\
\hline Estados Unidos & 74 & 21 & 5,6 & 1,6 & 40 \\
\hline Australia & 82 & 27 & 14,5 & 6,0 & 32 \\
\hline Alemania & 88 & 22 & 3,0 & 0,2 & 15 \\
\hline Francia & 88 & 19 & 1,9 & $\ldots$ & 43 \\
\hline Reino Unido & 70 & 18 & 8,8 & 3,2 & 33 \\
\hline Italia & 70 & 17 & 1,7 & 0,1 & 30 \\
\hline España & 76 & 24 & 2,6 & 0,3 & 34 \\
\hline Portugal & 76 & 19 & 3,4 & 0,6 & 27 \\
\hline
\end{tabular}

NotA:

Población escolarizada en cualquier nivel educativo.

FUENTE:

OECD, Education At a Glance (París: OECD, 2000), pp. 135-136.

dia de los países de OCDE. Pero de 20 a 29 años de edad España tiene el $24 \%$ de jóvenes estudiando, cuando la media es solamente del $20 \%$. Es decir, que España destaca por conseguir que las personas continúen estudios en su segunda década de vida por encima de la media de los países industrializados del mundo. A edades posteriores el modelo español mantiene tasas entre la mitad y la cuarta parte de la media de OCDE. España destaca por continuar la educación de adolescentes hasta la Universidad en mayor proporción de lo esperable, pero no realiza educación continuada de adultos con la misma intensidad.

En la última columna de la tabla se presenta el dato puntual de personas de 20 años de edad que están en educación terciaria. En el total de los países de la OCDE es algo más de una persona de cada cuatro (28\%), mientras que en España es una de cada tres (34\%). España destaca —sólo por detrás de Francia y Estados Unidos-por la proporción elevada de jóvenes de 20 años que están en la Universidad. Estos datos demuestran que la cantidad de población en España que está en educación terciaria es alta, mayor de la espera- 
da, a pesar de que el nivel general de educación de la población es bastante bajo. España mantiene un modelo polarizado que con el tiempo va a ir superándose, pero que al inicio del siglo XXI supone la máxima desigualdad esperable en el entorno de los países industrializados. Lógicamente, esa estructura puede ser conflictiva, tanto socialmente como en el mercado laboral. Es importante tener en cuanta la evolución de este proceso para interpretar de forma correcta una situación que en España es peculiar.

\section{DE EDUCACIÓN SUPERIOR A EDUCACIÓN TERCIARIA}

En lo referente a educación, el mundo parece desarrollarse por arriba. En los países industrializados la educación terciaria se expande muy deprisa, mientras que en los países menos desarrollados el analfabetismo se reduce lentamente. La tasa de escolarización terciaria en el mundo se duplica en tres décadas —entre 1970 y 2000_, pasando del $9 \%$ de la población al $17 \%$, mientras que el analfabetismo no se reduce a la mitad: pasa del 37 al $21 \%$. Esta visión general sugiere que las desigualdades pueden estar aumentando, aunque lógicamente hay que diferenciar países y regiones. Por ejemplo, el avance de España en educación terciaria es espectacular. En 1970 (con la Ley General de Educación de Villar Palasí, ministro de Franco), España tenía una tasa de escolarización universitaria del 9\%, igual a la media mundial. Treinta años después, España muestra una tasa de escolarización terciaria que es el triple que la media mundial: $51 \%$ respecto a $17 \%$. La expansión universitaria en España es, pues, una de las características más importantes de la estructura social española ${ }^{4}$. Este cambio social depende del punto de partida, que en el caso español es particularmente bajo.

Las desigualdades sociales y económicas entre los países del mundo disminuyen sensiblemente, pero aumentan las desigualdades dentro de cada país. En las tres ultimas décadas del siglo xx el mundo desarrollado duplica su tasa de escolarización terciaria, mientras que los países no-desarrollados la triplican (teniendo en cuenta que el punto de partida es mucho más bajo en éstos). En la tabla 5 se puede ver la evolución de las tasas de escolarización terciaria en el mundo entre 1970 y 1997. La situación de estancamiento más acusada se produce en Asia meridional. El progreso en Latinoamérica se ha ralentizado, sobre todo si se compara con el desarrollo universitario de Asia oriental (incluye Oceanía), que en tres décadas incrementa ocho veces su tasa de escolarización terciaria. A nivel educativo, las regiones que presentan un progreso más lento son Asia meridional y los países árabes. En ambos casos, la explicación no depende tanto del nivel de desarrollo económico como de la situación social de la mujer. Como la mujer representa la mitad de la po-

\footnotetext{
4 Véase Jesús M. de Miguel, Estructura y cambio social en España (Madrid: Alianza Editorial, 1998).
} 
TABLA 5

Evolución de las tasas de escolarización terciaria, 1970-1997

(En porcentajes)

\begin{tabular}{|c|c|c|c|c|c|}
\hline \multirow[b]{2}{*}{ Niveles de desarrollo } & \multicolumn{4}{|r|}{ Años } & \multirow{2}{*}{$\begin{array}{r}\text { Incremento } \\
\text { (1997 respecto } \\
\text { de } 1970)\end{array}$} \\
\hline & 1970 & 1980 & 1990 & 1997 & \\
\hline Total del mundo & 9 & 12 & 14 & 17 & 1,9 veces más \\
\hline Países desarrollados: & 26 & 36 & 44 & 52 & 2,0 \\
\hline Europa & 14 & 29 & 36 & 43 & 3,0 \\
\hline Países en desarrollo: & 3 & 5 & 7 & 10 & 3,6 \\
\hline Latinoamérica (a) & 6 & 14 & 17 & 19 & 3,1 \\
\hline Estados árabes & 4 & 10 & 11 & 15 & 3,5 \\
\hline Asia oriental (b) & 1 & 4 & 6 & 11 & 7,7 \\
\hline Asia meridional & 4 & 4 & 6 & 7 & 1,8 \\
\hline África subsahariana & 1 & 2 & 3 & 4 & 4,9 \\
\hline Países menos desarrollados (c): & 1 & 2 & 2 & 3 & 3,2 \\
\hline España & 9 & 23 & 37 & 51 (d) & 5,7 veces más \\
\hline
\end{tabular}

NOTAS:

«Escolarización terciaria» es la de «enseñanza superior», incluyendo, pues, toda la enseñanza universitaria. Se calcula con el número de estudiantes (de cualquier edad) por la población total cinco años después del final de la educación secundaria en cada país. Se expresa en porcentajes. Por ejemplo, para España es la población de 18 a 22 años de edad.

(a) Incluye Caribe.

(b) Asia del Este y Oceanía.

(c) Son 49 países que están incluidos en los 166 «países en desarrollo».

(d) En 1996.

FUENTE:

UNESCO, Statistical Yearbook 1999 (París: Unesco Publishing \& Bernan Press, 1999), II, pp. 18-20. Los datos para España en II, pp. 354-355.

blación, si la escolarización terciaria excluye a muchas mujeres es difícil que la tasa global se eleve. De ahí la importancia que para un análisis correcto de la educación terciaria tiene entender la situación de la mujer.

La expansión de la educación terciaria en España es enorme. En 1970, España está a la altura de la media mundial de escolarización terciaria (9\%). Treinta años después está muy por encima de la media del mundo, con una escolarización terciaria que en 1996 alcanza ya a más de la mitad de la población joven (51\%). Hay que tener en cuenta que la casi totalidad de esa educación terciaria en el caso español se realiza en la Universidad. La expansión se produce en los años setenta del siglo xx, en parte condicionada por la moderni- 
zación, el desarrollo económico, nuevos recursos educativos dedicados a la educación y, sobre todo, por la democratización política. La expansión se mantiene alta todavía en las dos décadas posteriores, a pesar incluso de la crisis económica. La expansión de la educación terciaria en España no parece detenerse con la crisis económica, sino que, al contrario, se refuerza por las tasas altas de desempleo juvenil y por la feminización súbita de la educación terciaria. Esos factores en España coinciden en el tiempo, en las dos últimas décadas del siglo xx. Al inicio del siglo XxI el sistema de educación terciaria español progresa hacia un modelo universal. No debe, pues, hablarse de «masificación» - como es habitual en los últimos años-, sino de «universalización» de la educación universitaria. El problema es si es posible universalizar la educación terciaria manteniendo la calidad. Por eso, la política pública actual sobre la Universidad trata con insistencia el tema de la calidad de la docencia y la excelencia de la investigación. Para lograr la universalización —más del $75 \%$ de las cohortes respectivas escolarizadas - es preciso mejorar la situación de la mujer. Los países en que la mujer mantiene una posición culturalmente retrasada no van a lograr la universalización terciaria.

La proporción de población con educación terciaria depende del desarrollo socioeconómico, pero también de la evolución histórica de las tasas de escolarización. Para ello es necesario realizar un análisis por cohortes. Los países más desarrollados tienen actualmente un $20 \%$ o más de población con estudios terciarios. Pero hace unos años la proporción era la mitad, así que la población de 55 a 64 años con estudios terciarios suele ser en torno a $10 \%$. No todos los países tienen la misma experiencia. En la tabla 6 se presentan datos sobre la población de 25 a 64 años de edad con educación terciaria. Frente a los países más desarrollados, que tienen un $20 \%$ de población adulta con estudios terciarios, los países europeos centrales (Alemania, Francia, Reino Unido) llegan como mucho al $15 \%$. A su vez, esta proporción es la mitad en los países europeos meridionales. Estamos acostumbrados a una situación de progreso lineal, en que cada año la situación de la educación terciaria mejora con respecto al año anterior: mayor calidad y alcanzando a más personas. En los países de la OCDE la media de población adulta con educación terciaria es del $14 \%$. Pero si se compara el grupo de 25-34 años de edad con el de 55-64 años la proporción es casi el doble: 1,8 veces de diferencia. Según se mide la situación en cohortes sucesivas de más edad hay menos casos de personas con estudios terciarios. Pero la experiencia de cada país no es siempre así. Estados Unidos tiene, por ejemplo, más casos de personas con estudios terciarios en el grupo de edad de 45 a 54 años; Alemania e Italia, más casos en la generación de 35-44 años de edad.

La diferencia porcentual entre los casos extremos señala la velocidad del cambio, así como el progreso conseguido. Hay factores de mortalidad física de personas de cohortes anteriores, pero en la población que se observa (25 a 64 años) esa disminución es reducida. Si se 
TABLA 6

Población de 25 a 64 años de edad con educación terciaria, en 1998 (En porcentajes)

\begin{tabular}{|c|c|c|c|c|c|}
\hline \multirow[b]{2}{*}{ Países } & \multirow{2}{*}{$\begin{array}{r}\text { Total de } \\
25 \text { a } 64 \text { años }\end{array}$} & \multicolumn{4}{|c|}{ Grupos de edad (en años) } \\
\hline & & $25-34$ & $35-44$ & $45-54$ & $55-64$ \\
\hline Media OCDE & 14 & 16 & 15 & 13 & 9 \\
\hline Japón & 18 & 23 & 23 & 15 & 9 \\
\hline Estados Unidos & 27 & 27 & 26 & 29 & 22 \\
\hline Australia & 17 & 19 & 18 & 16 & 10 \\
\hline Alemania & 14 & 14 & 16 & 15 & 10 \\
\hline Francia & 11 & 15 & 10 & 10 & 6 \\
\hline Reino Unido & 15 & 17 & 17 & 15 & 11 \\
\hline Italia & 9 & 9 & 11 & 9 & 5 \\
\hline España & 14 & 21 & 16 & 11 & 6 \\
\hline Portugal & 7 & 8 & 7 & 5 & 4 \\
\hline \multicolumn{6}{|c|}{ Mujeres: } \\
\hline Media OCDE & 12 & 16 & 13 & 10 & 6 \\
\hline Japón & 8 & 14 & 11 & 6 & 3 \\
\hline Estados Unidos & 25 & 29 & 26 & 26 & 18 \\
\hline Australia & 17 & 21 & 18 & 14 & 9 \\
\hline Alemania & 11 & 13 & 14 & 11 & 5 \\
\hline Francia & 9 & 15 & 9 & 8 & 4 \\
\hline Reino Unido & 14 & 16 & 15 & 13 & 9 \\
\hline Italia & 8 & 10 & 11 & 8 & 3 \\
\hline España & 14 & 24 & 16 & 9 & 4 \\
\hline Portugal & 7 & 10 & 7 & 5 & 4 \\
\hline
\end{tabular}

NOTA:

Incluye educación terciaria de tipo A (de segundo ciclo).

FUENTE:

OECD, Education At a Glance (París: OECD, 2000), pp. 36-37.

comparan los dos grupos extremos (25-34 con 55-64 años) el progreso máximo de todos los países industrializados del mundo lo representa España, con 3,5 veces más casos en el grupo de edad de 25-34 años que en el de 55-64: en concreto, $21 \%$ en el primer grupo y $6 \%$ en el segundo con estudios terciarios. A España le sigue Japón, con diferencias de 2,6 
veces (entre 23 y 9\%), y después Francia, 2,5 veces (entre 15 y 6\%). El progreso realizado por España es, pues, considerable, pero supone también tensiones en la sociedad que son evidentes.

Todavía hay posibilidades de progreso en el mundo industrializado. En los países de la OCDE la proporción de mujeres con estudios terciarios (12\%) es menor que la media (14\%). Sin embargo, el progreso que se observa entre las diversas cohortes de mujeres es más rápido y elevado que la media (que incluye una mayoría de varones). Frente a una diferencia de 1,8 veces en la media entre cohortes extremas (25-34 versus 55-64), en el caso de las mujeres la diferencia de la media de los países de OCDE es 2,7 veces. Pero lo significativo es que - por vez primera en la historia - en el grupo de edad de 25 a 34 años de edad ya no hay diferencias entre varones y mujeres en la población con estudios terciarios: en ambos casos es el $16 \%$.

Entre las mujeres el progreso es también máximo en el caso de España, con diferencias entre cohortes extremas de seis veces (24 a 4\%). A España le sigue Japón, con 4,7 veces de diferencia ( $14 \%$ versus $3 \%$ ), y Francia, con 3,8 veces (15\% frente a $4 \%$ ). En el grupo de edad más joven de la tabla -25 a 34 años de edad-, España es el segundo país con más mujeres con educación terciaria (24\%), sólo superado por Estados Unidos (que tiene $29 \%$ ). La situación de Japón, que ha experimentado un progreso similar al español aunque un poco menor en cuanto a las mujeres, es menos positiva. Apenas tiene un $14 \%$ de mujeres jóvenes (25-34 años de edad) con estudios superiores. A pesar del desarrollo nipón (es la primera renta per capita mundial, con la esperanza de vida mayor del planeta), muestra diferencias considerables por género en sus tasas de educación terciaria. Tiene un $18 \%$ de la población adulta con estudios superiores, bastante por debajo de Estados Unidos, que alcanza el $27 \%$; pero entre las mujeres son sólo el $8 \%$ de las japonesas. Incluso en el grupo de edad más joven (25-34 años), la media relativamente alta del $23 \%$ de japoneses con estudios terciarios baja a $14 \%$ en el caso de las mujeres (versus $24 \%$ en el caso de las españolas).

Unos países están logrando superar las desigualdades de género en educación terciaria, y otros no lo consiguen a pesar de su desarrollo económico y recursos educativos. Los países asiáticos y los islámicos mantienen un retraso considerable en la igualdad de la mujer. Son pocos los países del mundo que no tienen diferencias numéricas por género. Australia ya no presenta diferencias por género, y en el grupo más joven (25-34 años) incluso hay más mujeres que varones con estudios terciarios. España es otro de los pocos países que no tienen ya diferencias por género en educación terciaria, con más mujeres que varones en el grupo de edad más joven (25-34 años). El proceso de feminización de la educación terciaria es un factor importante, que condiciona las tasas generales de escolarización ter- 
ciaria en un país. No es posible lograr un proceso de universalización en educación terciaria sin equilibrar los dos géneros. España es una muestra de progreso en ambas cuestiones: equilibrar los géneros y expandir decididamente la proporción de población con estudios terciarios. Es un caso de éxito considerable en el contexto internacional de la educación terciaria.

En los países industrializados el progreso ha sido lineal en las últimas décadas del siglo xx, con un esfuerzo máximo en los años setenta de dicho siglo, pero conservando bastante la aceleración del progreso. En la ultima década del siglo xx se atraviese ya el listón del $50 \%$ en la tasa de escolarización terciaria. Parece que en la década de los noventa se produce una cierta ralentización del proceso, aunque no está todavía clara. La tabla 7 muestra la evolución del número de estudiantes matriculados en educación terciaria durante la última década del siglo xx (los años noventa) en los países de la OCDE. Numéricamente supone una expansión de la educación terciaria, que en números índices de los años 1990 y 1997 pasa de 100 a 149. Para una visión global se puede trabajar con datos absolutos ya que las cohortes jóvenes de los países industrializados apenas cambian (pasan de 100 a 101 en los años noventa). El incremento de estudiantes matriculados en educación terciaria se

TABLA 7

Evolución del número de estudiantes matriculados en educación terciaria, durante la última década del siglo xx

Incremento debido al cambio en

\begin{tabular}{|c|c|c|c|}
\hline \multirow{2}{*}{ Países } & \multirow{2}{*}{$\begin{array}{r}\text { Matriculados en } \\
\text { educación terciaria } \\
\text { en } 1997(1990=100)\end{array}$} & \\
\hline & & $\begin{array}{l}\text { El tamaño de la } \\
\text { cohorte de jóvenes }\end{array}$ & $\begin{array}{r}\text { La tasa de } \\
\text { matriculación }\end{array}$ \\
\hline Media de países OCDE & 149 & 101 & 149 \\
\hline Japón & $\ldots$ & $\ldots$ & \\
\hline Estados Unidos & 106 & 96 & 108 \\
\hline Australia & 134 & 102 & 131 \\
\hline Alemania & 106 & $\ldots$ & \\
\hline Francia & 130 & 95 & 138 \\
\hline Reino Unido & 188 & 92 & 201 \\
\hline Italia & 135 & 98 & 138 \\
\hline España & 144 & 101 & 144 \\
\hline Portugal & 268 & 105 & 257 \\
\hline
\end{tabular}

FUENTE:

OECD, Education At a Glance (París: OECD, 2000), p. 160. 
debe principalmente al aumento del número de mujeres y de personas de clases bajas. Se está produciendo, pues, un proceso de democratización, que camina paralelo al proceso de feminización y al proceso de universalización de la educación terciaria.

España en los años noventa se comporta como la media de los países de la OCDE, consiguiendo en el año 1997 tener ya 144 estudiantes matriculados por cada 100 en 1990. La media de la OCDE es de 149, muy similar. A pesar de la expansión de la Universidad en España en la segunda mitad del siglo xx, la situación en los años noventa se estabiliza. La mayoría de los países se comportan de manera parecida, intuyéndose un proceso de convergencia. Está el caso peculiar de Portugal, con un incremento elevado del número de estudiantes terciarios (su punto de partida es bastante menor), pero es debido en parte a un crecimiento del tamaño de las cohortes jóvenes. En el caso del Reino Unido, no depende ya del incremento de la cohorte (pues en realidad desciende de 100 a 92), sino de un incremento considerable del número de personas que se matriculan (de 100 pasan a 201).

España sigue progresando, pero entra ya a formar parte de la pauta convergente de los países más industrializados, especialmente los de la Unión Europea. Parece que el rápido proceso de incremento del número de estudiantes finaliza, algo que en las décadas anteriores se define en España como «masificación de la Universidad». Aunque esto no significa que se detenga el progreso de ampliación de estudios terciarios a mujeres y a clases bajas, pues continúa aunque a un ritmo no tan acelerado. Los avances en la escolarización (terciaria) parecen seguir una pauta tipo muelle. La incorporación de la mujer supuso un avance. Ahora el progreso depende de la incorporación de clases bajas, que es más complicada de conseguir. Las clases medias y altas ya tienen a sus hijos/as en la Universidad. Pero las clases bajas necesitan ayuda económica, una motivación especial y un cambio de valores en la sociedad. El presupuesto público para educación terciaria es así un factor vital para continuar con el progreso en el sistema de educación terciaria.

\section{GASTO EN UNIVERSIDAD}

Las diferencias de población y de riqueza entre los países del mundo son considerables. Las Naciones Unidas, a través del Statistical Yearbook, ofrece datos para 219 países. El anuario diferencia entre países «desarrollados» (uno de cada cuatro) y países «en desarrollo» (en español se utiliza la expresión «en vías de desarrollo»). Este último concepto es un eufemismo, pues no queda claro si esos 166 países están todos realmente desarrollándose. Quizás por ello, de ese grupo, Naciones Unidas desgaja una serie de países (un tercio) que denomina países «menos desarrollados». La idea que se transmite es que el mundo entero se desarrolla, aunque algunos países están adelantados y otros retrasados. 
A nivel educativo la situación mundial mejora mucho, con una reducción significativa de la tasa de analfabetismo. En el otro extremo del espectro educativo, la enseñanza terciaria no sólo depende de la riqueza del país y de las inversiones del sector público, sino también de los niveles de desigualdad social, étnica y de género de cada país.

La tabla 8 resume las diferencias de población y riqueza en el mundo hacia el año 2000. En el mundo desarrollado destaca Estados Unidos, con una población de 268 millones de habitantes (censados legalmente). La Unión Europea, con 371 millones de población, es un tercio mayor que Estados Unidos. Rusia -147 millones de habitantes- es casi la mitad que Estados Unidos. Japón es el octavo país del mundo en población, con 126 millones de habitantes. No todos los países centrales son grandes. Australia es un ejemplo de país importante a nivel económico y cultural, con sólo 18 millones de habitantes. Canadá tiene 30 millones de habitantes, y un sistema de educación terciaria progresivo. Dentro de la Europa industrializada, España tiene casi 40 millones de habitantes, menos de la mitad que Alemania (82 millones), pero es el quinto país más grande de la Unión Europea. Una de cada diez personas en la Unión Europea es española, y es español uno/a de cada siete estudiantes europeos. El problema del desarrollo no es sólo de riqueza, sino también de tamaño relativo. Algunos países «en desarrollo» están además muy poblados. Asia es un continente con mucha población. China es el primer país del mundo, con 1.244 millones de habitantes, es decir, más de tres veces la Unión Europea, o casi cinco veces la población de Estados Unidos. Le sigue India, con 955 millones: mayor que la Unión Europea, Estados Unidos, Rusia y Japón juntos. India tiene tres cuartas partes de la población de China. En el año 2015 se calcula que China tendrá 1.410 millones de habitantes, e India, 1.230 millones. España retrocederá a 39 millones $^{5}$.

Las diferencias de riqueza en el mundo son también considerables. En PNB per capita hay diferencias de hasta quinientas veces entre los países extremos. Lógicamente, no puede esperarse que tengan sistemas educativos similares. El país más rico del mundo es Japón, con 32.000 dólares de $\mathrm{PNB}^{6}$. El segundo país es Estados Unidos, que es la primera potencia económica mundial, con 31.000 dólares de renta per capita. Sigue la Unión Europea, cuyos países integrantes presentan bastante variabilidad, oscilando entre 11.000 y 45.000 dólares de renta per capita, es decir, una diferencia de cuatro veces entre los extremos. Pero la mayoría de los países europeos tienen entre 20.000 y 30.000 dólares de renta per capita. España tiene 14.000 dólares de renta per capita, siendo el tercero por la cola de los países de la Unión Europea. España, Grecia y Portugal forman el bloque de países euro-

5 United Nations Development Programme (2002), pp. 162-164.

6 En realidad, el primer país del mundo es Luxemburgo (parte de la Unión Europea), con 45.000 dólares de renta per capita. Pero es un país peculiar, de cuatrocientos mil habitantes, y un sistema universitario propio muy reducido. 
TABLA 8

Diferencias de población y riqueza en el mundo, circa 2000

\begin{tabular}{|c|c|c|c|c|c|c|}
\hline \multirow[b]{2}{*}{ Países } & \multirow{2}{*}{$\begin{array}{r}\text { Población } \\
\text { (en millones } \\
\text { de habitantes) }\end{array}$} & \multirow{2}{*}{$\begin{array}{r}\text { PNB } \\
\text { per capita } \\
\text { (en miles } \\
\text { de dólares } \\
\text { anuales) }\end{array}$} & \multicolumn{2}{|c|}{$\begin{array}{r}\text { Porcentaje de } \\
\text { ingresos de la población }\end{array}$} & \multirow{2}{*}{$\begin{array}{r}\text { Número } \\
\text { de veces de } \\
\text { diferencia }(d)\end{array}$} & \multirow{2}{*}{$\begin{array}{r}\text { Índice } \\
\text { de Gini } \\
\text { (por cien) }\end{array}$} \\
\hline & & & $\begin{array}{r}20 \% \\
\text { más rica }\end{array}$ & $\begin{array}{r}20 \% \\
\text { más pobre }\end{array}$ & & \\
\hline \multicolumn{7}{|l|}{ Países desarrollados: } \\
\hline Estados Unidos & 268 & 30,6 & 46 & 5 & 9 & 41 \\
\hline Unión Europea (a): & 371 & $\ldots$ & $\ldots$ & $\cdots$ & $\cdots$ & $\ldots$ \\
\hline Luxemburgo & 0,4 & 44,6 & 36 & 9 & 4 & 27 \\
\hline Dinamarca & 5 & 32,0 & 34 & 10 & 4 & 25 \\
\hline Austria & 8 & 26,0 & 33 & 10 & 3 & 23 \\
\hline Alemania & 82 & 25,4 & 38 & 8 & 5 & 30 \\
\hline Suecia & 8 & 25,0 & 34 & 10 & 4 & 25 \\
\hline Bélgica & 10 & 24,5 & 34 & 10 & 4 & 25 \\
\hline Países Bajos & 16 & 24,3 & 40 & 7 & 5 & 33 \\
\hline Finlandia & 5 & 23,8 & 36 & 10 & 4 & 26 \\
\hline Francia & 59 & 23,5 & 40 & 7 & 6 & 33 \\
\hline Reino Unido & 58 & 22,6 & 43 & 7 & 6 & 36 \\
\hline Italia & 57 & 20,1 & 36 & 9 & 4 & 27 \\
\hline Irlanda & 4 & 19,2 & 43 & 7 & 6 & 36 \\
\hline España & 39 & 14,0 & 40 & 8 & 5 & 32 \\
\hline Grecia & 10 & 11,8 & 40 & 8 & 5 & 33 \\
\hline Portugal & 10 & 10,6 & 43 & 7 & 6 & 36 \\
\hline \multicolumn{7}{|l|}{ Europa del Este: } \\
\hline República Checa & 10 & 5,1 & 36 & 10 & 3 & 25 \\
\hline Hungría & 10 & 4,6 & 40 & 9 & 4 & 31 \\
\hline Polonia & 39 & 4,0 & 41 & 8 & 5 & 33 \\
\hline Federación de Rusia & 147 & 2,3 & 54 & 4 & 12 & 49 \\
\hline \multicolumn{7}{|l|}{ Otros desarrollados: } \\
\hline Japón & 126 & 32,2 & 36 & 11 & 3 & 25 \\
\hline Australia & 18 & 20,0 & 41 & 6 & 7 & 35 \\
\hline Canadá & 30 & 19,3 & 39 & 8 & 5 & 32 \\
\hline Israel & 6 & 17,4 & 42 & 7 & 6 & 36 \\
\hline
\end{tabular}

Países en desarrollo:

Latinoamérica:

Argentina

México

Brasil

Venezuela
36

96

160

23

\section{7,6}

... (b)

4,4

3,7
59

64

53
41

27

25

23

30

25

25

33

26

33

36

27

32

33

36

25

31

33

49 
TABLA 8

\section{Continuación}

\begin{tabular}{|c|c|c|c|c|c|c|}
\hline \multirow[b]{2}{*}{ Países } & \multirow{2}{*}{$\begin{array}{r}\text { Población } \\
\text { (en millones } \\
\text { de habitantes) }\end{array}$} & \multirow{2}{*}{$\begin{array}{r}\text { PNB } \\
\text { per capita } \\
\text { (en miles } \\
\text { de dólares } \\
\text { anuales) }\end{array}$} & \multicolumn{2}{|c|}{$\begin{array}{r}\text { Porcentaje de } \\
\text { ingresos de la población }\end{array}$} & \multirow{2}{*}{$\begin{array}{r}\text { Número } \\
\text { de veces de } \\
\text { diferencia (d) }\end{array}$} & \multirow{2}{*}{$\begin{array}{r}\text { Índice } \\
\text { de Gini } \\
\text { (por cien) }\end{array}$} \\
\hline & & & $\begin{array}{r}20 \% \\
\text { más rica }\end{array}$ & $\begin{array}{r}20 \% \\
\text { más pobre }\end{array}$ & & \\
\hline \multicolumn{7}{|l|}{ Asia: } \\
\hline República de Corea & 46 & 8,5 & 39 & 8 & 5 & 32 \\
\hline Turquía & 64 & 2,9 & 48 & 6 & 8 & 42 \\
\hline China & 1.244 & 0,78 & 47 & 6 & 8 & 40 \\
\hline India & 955 & 0,45 & 46 & 8 & 6 & 38 \\
\hline \multicolumn{7}{|l|}{ África: } \\
\hline Sudáfrica & 43 & 3,2 & 65 & 3 & 22 & 59 \\
\hline Argelia & 29 & 1,6 & 43 & 7 & 6 & 35 \\
\hline Egipto & 62 & 1,4 & 39 & 10 & 4 & 29 \\
\hline Marruecos & 27 & 1,2 & 47 & 6 & 7 & 40 \\
\hline
\end{tabular}

Países menos desarrollados:

$\begin{array}{lllllrr}\text { Tanzania (República Unida de) } & 31 & 0,24 & 46 & 7 & 7 & 38 \\ \text { Mozambique } & 18 & 0,23 & 46 & 6 & 7 & 40 \\ \text { Níger } & 10 & 0,19 & 53 & 3 & 20 & 50 \\ \text { Etiopía } & 60 & 0,10 \text { (c) } & 48 & 7 & 7 & 40\end{array}$

NOTAS:

(a) La población de Estados Unidos es 268 millones de personas, Unión Europea es 371 millones (38\% más que Estados Unidos).

(b) No hay dato. EI PIB de México es 7,7 miles de dólares per capita, estimado por la UNESCO para el año 2000.

(c) Supone, pues, 100 dólares de PNB per capita.

(d) Número de veces entre el $20 \%$ más rico y el $20 \%$ más pobre. Para su cálculo se tienen en cuenta los datos exactos, con decimales.

\section{FUENTES:}

UNESCO, Statistical Yearbook 1999 (París: Unesco Publishing \& Bernan Press, 1999); United Nations, Demographic Yearbook 1997 (Nueva York: United Nations, 1999), pp. 118-123; Banco Mundial, http://devdata.worldbank.org (consultado 2 noviembre 2000); Banco Mundial, http://www.worldbank.org/poverty/data/trends/inequal.htm (11 febrero 2001).

peos meridionales con menor desarrollo, aunque ya plenamente industrializados. Otros países desarrollados en el mundo - como Australia, Canadá o Israel- están a nivel europeo. Sin embargo, la situación de la Europa del Este es bastante inferior a Europa Occidental. La Federación de Rusia tiene 2.300 dólares de renta per capita, es decir, catorce veces menos que Japón, trece veces menos que Estados Unidos, o incluso seis veces menos que España. Los países del Este se consideran industrializados (desarrollados) pero con niveles de riqueza bajos. 
Los países «en desarrollo» están todos por debajo de los 10.000 dólares de renta per capita; y, dentro de ellos, los países «menos desarrollados» no alcanzan ni los 500 dólares anuales. La situación de esos 49 países es socialmente problemática. Dentro de cada región del mundo en desarrollo hay algún país que destaca económicamente. En Asia, República de Corea (Corea del Sur) alcanza 6.500 dólares de renta per capita. En Latinoamérica destaca Argentina, con 7.600. En el continente africano, Sudáfrica sobresale con 3.200 dólares de renta per capita. El resto de los países dentro de esos continentes son más homogéneos. En el contexto asiático, Japón destaca de forma impresionante: es el país con el PNB per capita más alto del mundo. Tiene una riqueza que es 72 veces mayor que India, 41 veces más que China, e incluso cuatro veces más que República de Corea. Japón tiene un PNB per capita que es 2,3 veces mayor que el de España, país con el que comparte algunas características de crecimiento económico tardío pero acelerado (lo que a veces se denomina «milagro económico»). En el contexto mundial, Japón es «el otro modelo» de desarrollo industrial, un país económicamente exitoso. Los países del norte de África tienen un PNB per capita que es aproximadamente veinte veces menor que la media de la Unión Europea. Incluso si se comparan los países de Europa meridional con los del norte de África, la diferencia en renta per capita es por lo menos diez veces. Por ejemplo, España aventaja a Marruecos en renta per capita en 12 veces, Francia a Argelia en 15 veces, e Italia a Egipto en 14 veces. Es, pues, lógico esperar tensiones en la región. Las diferencias en educación terciaria en ambas riberas del Mar Mediterráneo son, lógicamente, elevadas ${ }^{7}$.

No es sólo un problema de desigualdades de población y de riqueza entre países, sino también de desigualdades económicas dentro de cada país. La educación terciaria viene condicionada por los tres indicadores. La tabla incluye datos del Banco Mundial, mostrando la proporción de ingresos nacionales del $20 \%$ de personas entre las más ricas del país, comparándolo con el $20 \%$ de personas de entre las más pobres. Una de cada cinco personas es una proporción considerable que no incluye únicamente a élites poderosas, ni sólo a personas marginales excluidas del sistema. Siendo un grupo extenso de población, la comparación tiene más utilidad para medir la desigualdad estructural que si se escogiesen extremos de 10 ó 5\%. En Estados Unidos, por ejemplo, la quinta parte más rica de la población posee casi la mitad de los ingresos (46\%), mientras que la quinta parte más pobre ingresa solamente el $5 \%$. Hay, pues, nueve veces de diferencia entre ricos y pobres. Las proporciones correlativas en España son el 40 y el 8\%, es decir, que en España los ricos son relativamente menos ricos y los pobres relativamente menos pobres. Hay cinco veces de diferencia entre los extremos. Se puede calcular con más exactitud el índice de Gini (que se incluye en la última columna), pero el indicador número de veces de diferencia entre los dos grupos extremos (ricos/pobres) es útil.

\footnotetext{
7 Un estudio excelente es Jordi Caïs, El desarrollo invisible (Barcelona: tesis doctoral en la Universitat de Barcelona, 1999).
} 
Se observan varias pautas de desigualdad económica — de ingresos anuales- en el mun$\mathrm{do}^{8}$. La primera conclusión es que el mundo desarrollado es menos desigual. Sobre todo la Unión Europea es bastante igualitaria, pues las diferencias entre ricos/pobres dentro de sus países oscilan entre tres veces (Austria) y seis veces (Reino Unido). En el contexto europeo, España es un país intermedio, con cinco veces de diferencia entre ricos/pobres; un país más igualitario de lo que se supone a menudo. Frente a la Unión Europea —que es la región mundial más igualitaria-, Estados Unidos destaca como un país bastante desigual, con nueve veces de diferencia entre ricos/pobres. Pero esta desigualdad no es una consecuencia del hecho de ser un país extraordinariamente rico (y capitalista). Japón es uno de los países económicamente más igualitarios del mundo, con sólo tres veces de diferencia entre los extremos. En ese sentido, Japón es un poco menos igualitario que Austria, y está al mismo nivel que Suecia o Dinamarca. Sin embargo, otro país rico como es Australia resulta bastante desigual (siete veces de diferencia). Los países de Europa del Este son tan igualitarios como la Unión Europea, salvo la Federación de Rusia, que alcanza la máxima desigualdad en Europa, con 12 veces de diferencia entre ricos/pobres; una desigualdad superior a la que existe en Estados Unidos. En Rusia, el 20\% de población más rica concentra el $54 \%$ de los ingresos y, en cambio, el $20 \%$ más pobre tiene sólo el $4 \%$ de los ingresos. Es una situación difícilmente sostenible dentro del contexto europeo, que es bastante igualitario.

Los países «en desarrollo» se caracterizan por mostrar una más o menos acusada desigualdad económica dentro del país, aunque la varía de unos a otros. La región más desigual de todas es Latinoamérica. Brasil alcanza 26 veces de diferencia entre ricos y pobres. El $20 \%$ más pobre de la población sólo obtiene el $2 \%$ de los ingresos. Toda Latinoamérica es desigual, aunque curiosamente no se refleja tanto en su sistema educativo; sufre desigualdad económica pero no tanto desigualdad educativa por género. En cambio, Asia presenta pocas desigualdades económicas intrapaíses. Los países asiáticos son un poco menos igualitarios que los de la Unión Europea, y más igualitarios que Estados Unidos. República de Corea tiene cinco veces de diferencia entre ricos/pobres, igual que España. Pero los países asiáticos muestran diferencias altas por género. África es una mezcla. Sudáfrica, que es el país más rico en ese continente, es muy desigual (22 veces de diferencias internas). El mundo árabe parece ser bastante igualitario económicamente. Egipto tiene sólo cuatro veces de diferencia entre ricos/pobres, y Marruecos siete. Los países llamados «menos desarrollados» no muestran una pauta única de desigualdad económica.

Los países industrializados del mundo han logrado desigualdades económicas menores entre ellos, sobre todo en la Unión Europea. La situación es peor en países con inmigra-

8 Estos datos no incluyen patrimonio y, en algunos casos, están calculados sobre los gastos cuando no hay datos de ingresos. 
ción - como Estados Unidos o Australia-, en donde, a pesar del desarrollo, los niveles de desigualdad económica de la población son altos. Son países capitalistas (y consumistas), pero también lo es Japón y, sin embargo, es un país igualitario, similar a Escandinavia, que incluye los países más igualitarios del mundo y con el mejor human development index 9 . América es un continente desigual. En el contexto de los países europeos, España es un país no demasiado rico, pero con un nivel medio-bajo de desigualdad social: tiene 14.000 dólares de renta per capita, y cinco veces de diferencia entre los ingresos del $20 \%$ más rico y el $20 \%$ más pobre de la población. Tradicionalmente ha dedicado menos recursos públicos a educación, pero el éxito del sistema proviene seguramente de que no existen desigualdades económicas profundas en el país. España comparte con Japón el «milagro económico» y un cierto "milagro educativo». La riqueza de un país tiene un efecto considerable sobre el nivel educativo de la población ( $\mathrm{y}$ al revés), pero el sistema de educación terciaria depende de factores sociales y políticos.

Una hipótesis sería que el nivel de riqueza de un país no condiciona el gasto relativo en educación. Los países gastan dinero en educación - y en educación terciaria- de forma variable. Hay alguna pauta que se puede deducir de la influencia del desarrollo, pero esa influencia no es sistemática. La tabla 9 presenta los datos de gastos en educación en el mundo. Los países desarrollados gastan entre el 3 y el $8 \%$ del PNB en el sistema educativo; la variación de casi tres veces va desde Grecia hasta Suecia. Tradicionalmente, los países escandinavos gastan mucho en educación y, en general, en el área social. Los gastos del Gobierno en educación son más variables que los gastos en relación con el PNB, lógicamente, pues dependen de la política específica de cada Gobierno: varían entre el 6 y el $25 \%$. En el mundo desarrollado el gasto público en educación varía 4,2 veces entre países. La política del Estado es, pues, más variable - y menos predecible- que el nivel de desarrollo del país.

En Europa se observa una cierta pauta norte/sur: los países septentrionales gastan mucho en educación, el doble que los meridionales. Los países que más recursos económicos utilizan son los escandinavos, y los que menos los de Europa del Sur. España gasta el 5\% del PNB en educación, y el $11 \%$ de los gastos del Gobierno. Ambas cantidades son mediasbajas. Los recursos públicos en educación en España son bastante escasos. La tendencia es que los países más ricos gastan relativamente más, lo que no tendría por qué ser así. Pero hay numerosas excepciones a esta pauta. Por ejemplo, Japón gasta poco en educación, apenas el 3,6\% del PNB, y solamente el $10 \%$ de los gastos gubernamentales. Éstas son proporciones incluso menores que las de España. Se podría argumentar que el siste-

9 Los diez países con un HDI (índice de desarrollo humano) más alto en el mundo son: Noruega, Suecia, Canadá, Bélgica, Australia, Estados Unidos, Islandia, Holanda, Japón y Finlandia. España está en el puesto 21. 
TABLA 9

Gastos en educación, circa 1997

(En porcentajes)

\begin{tabular}{|c|c|c|c|c|c|}
\hline \multirow[b]{2}{*}{ Países } & \multicolumn{2}{|c|}{$\begin{array}{l}\text { Gastos en educación } \\
\text { como porcentaje de }\end{array}$} & \multicolumn{3}{|c|}{$\begin{array}{r}\text { Porcentaje del gasto público ordinario } \\
\text { en educación, por niveles (a) }\end{array}$} \\
\hline & EI PNB & $\begin{array}{r}\text { Los gastos } \\
\text { del Gobierno }\end{array}$ & Primaria & Secundaria & Terciaria \\
\hline \multicolumn{6}{|l|}{ Países desarrollados: } \\
\hline Estados Unidos & 5,4 & 14 & 32 & 36 & 25 \\
\hline \multicolumn{6}{|l|}{ Unión Europea: } \\
\hline Luxemburgo & 4,0 & 15 & $34(d)$ & 43 & 5 \\
\hline Dinamarca & 8,1 & 13 & 22 & 39 & 22 \\
\hline Austria & 5,4 & 10 & 21 & 49 & 21 \\
\hline Alemania & 4,8 & 10 & $\ldots$ & $\ldots$ & 22 \\
\hline Suecia & 8,3 & 12 & 27 & 39 & 27 \\
\hline Bélgica & 3,1 & 6 & 21 & 46 & 22 \\
\hline Países Bajos & 5,1 & 10 & 24 & 40 & 29 \\
\hline Finlandia & 7,5 & 12 & 24 & 36 & 29 \\
\hline Francia & 6,0 & 11 & 20 & 50 & 18 \\
\hline Reino Unido & 5,3 & 12 & 30 & 44 & 24 \\
\hline Italia & 4,9 & 9 & 24 & 49 & 15 \\
\hline Irlanda & 6,0 & 14 & 24 & 42 & 24 \\
\hline España & 5,0 & 11 & 26 & 48 & 17 \\
\hline Grecia & 3,1 & 8 & $\ldots$ & 38 & 25 \\
\hline Portugal & 5,8 & 12 & 32 & 42 & 16 \\
\hline \multicolumn{6}{|l|}{ Europa del Este: } \\
\hline República Checa & 5,1 & 14 & 19 & 50 & 16 \\
\hline Hungría & 4,6 & 7 & 22 & 46 & 16 \\
\hline Polonia & 7,5 & 25 & 31 & $15(e)$ & $11(\mathrm{e})$ \\
\hline Federación de Rusia & 3,5 & 10 & $\ldots$ & 57 & 19 \\
\hline \multicolumn{6}{|l|}{ Otros desarrollados: } \\
\hline Japón & 3,6 & 10 & 37 & 42 & 12 \\
\hline Australia & 5,5 & 14 & 29 & 39 & 30 \\
\hline Canadá & 6,9 & 13 & $\ldots$ & $\ldots$ & 35 \\
\hline Israel & 7,6 & 12 & 34 & 31 & 18 \\
\hline
\end{tabular}

Países en desarrollo:

Latinoamérica:

Argentina

México

Brasil

Venezuela
3,5

4,9

5,1

5,2
13

23

19 (b)

22
39

41

48

48

$\begin{array}{ll}35 & 20 \\ 32 & 17 \\ 20 & 26 \\ & 35\end{array}$


TABLA 9

Continuación

\begin{tabular}{|c|c|c|c|c|c|}
\hline \multirow[b]{2}{*}{ Países } & \multicolumn{2}{|c|}{$\begin{array}{l}\text { Gastos en educación } \\
\text { como porcentaje de }\end{array}$} & \multicolumn{3}{|c|}{$\begin{array}{r}\text { Porcentaje del gasto público ordinario } \\
\text { en educación, por niveles (a) }\end{array}$} \\
\hline & EI PNB & $\begin{array}{r}\text { Los gastos } \\
\text { del Gobierno }\end{array}$ & Primaria & Secundaria & Terciaria \\
\hline \multicolumn{6}{|l|}{ Asia: } \\
\hline República de Corea & 3,7 & 18 & 44 & 37 & 8 \\
\hline Turquía & 2,2 & 15 & 43 & 22 & 35 \\
\hline China & 2,3 & 12 & 36 & 32 & 16 \\
\hline India & 3,2 & 12 & $\ldots$ & 26 & 14 \\
\hline \multicolumn{6}{|l|}{ África: } \\
\hline Sudáfrica & 8,0 & 24 & 42 & 30 & 14 \\
\hline Argelia & 5,1 & 16 & 28 & 25 & 17 \\
\hline Egipto & 4,8 & 15 & $\ldots$ & $\ldots$ & 33 \\
\hline Marruecos & 5,3 & 25 & $\ldots$ & 49 & 16 \\
\hline
\end{tabular}

Países menos desarrollados:

Tanzania (República Unida de) Mozambique (c)

Níger

Etiopía
3,4 (c)

4,1

2,3

4,0
11 (c)

12

13

14

$\begin{array}{cc}\ldots & 32 \\ 50 & 16 \\ \ldots & 32 \\ \ldots & 24\end{array}$

17

10

... 16

NOTAS:

(a) No tiene por qué sumar $100 \%$ ya que existe pre-primaria, otros tipos y sin distribución. Por ejemplo, en España los tres niveles básicos suman $91 \%$.

(b) Dato para 1985

(c) Datos de 1990. Hay $20 \%$ de no distribuido por niveles.

(d) Corresponde a 1989.

(e) Polonia tiene $36 \%$ no distribuido.

(f) Los datos por niveles son de 1980.

FUENTE:

Unesco, Statistical Yearbook 1999 (París: Unesco Publishing \& Bernan Press, 1999), II, pp. 490-532.

ma nipón es barato (paga mal al profesorado, por ejemplo), o que está bastante privatizado. La Federación de Rusia gasta igualmente poco. Bélgica destaca también por tener un gasto bastante bajo. En el otro extremo, todos los países escandinavos gastan mucho en educación, en torno al $8 \%$ del PNB.

Los países «en desarrollo» no tienen un gasto relativo del PNB diferente de los países desarrollados. El dato resulta sorprendente. Gastan entre el 2 y el $8 \%$ del PNB, lo que no les diferencia de los desarrollados, aunque son algo más variables. En gastos del Gobierno los países en desarrollo gastan más que los desarrollados, pero ese gasto varía menos 
entre países: desde el 12 al 24\% de los gastos del Gobierno. La hipótesis es que los recursos dedicados a educación globalmente, como los recursos estatales, no difieren mucho en proporción (y variación) respecto del nivel de desarrollo de los países del mundo. Existe una pauta común, con una variación también similar. No es, pues, un problema de recursos relativos.

Si se distinguen las diversas etapas de la educación, se observa que casi todos los países realizan un gasto público similar: alrededor de un tercio de los recursos de educación van a primaria, algo más de un tercio a secundaria, y aproximadamente una cuarta parte del presupuesto público a educación terciaria. La secundaria suele concentrar más estudiantes, y también más recursos. En los países desarrollados, el gasto público de educación en el nivel terciario representa entre el 12 y el $35 \%$, es decir, diferencias de tres veces. Varía, pues, mucho, lo que impide establecer un modelo convergente de recursos públicos. Se observa una cierta relación - tenue- entre desarrollo económico y gastos públicos en educación terciaria. Los países más ricos suelen gastar más recursos públicos en la Universidad, pero hay excepciones numerosas. Gastan relativamente menos países como Italia, España, Portugal, Japón e Israel. Los países «nuevos» (Australia, Canadá o Estados Unidos) y los países escandinavos gastan muchos recursos públicos en educación terciaria. Pero la razón es que ambos tienen las tasas máximas de población universitaria en el mundo. España se caracteriza por la escasez de recursos económicos en educación. La proporción del gasto respecto del PNB es apenas el 5\%; y respecto de los gastos del Gobierno, solamente el $11 \%$. Por niveles, el sector público español gasta relativamente poco en primaria (26\%), mucho en secundaria (48\%) y bastante poco en Universidad (17\%). El gasto público español en educación terciaria es relativamente el menor en Europa, junto con Italia y Portugal.

El gasto público en educación terciaria en los países «en desarrollo» varía mucho: entre el 8 y el 35\% (4,4 veces). No se observa una pauta clara, pero esa proporción es similar a la de los países desarrollados. La situación mundial de la educación terciaria no parece ser un problema de la distribución porcentual de gastos públicos. Puede afirmarse que los países pobres gastan bastante en Universidad. Por ejemplo, Venezuela gasta en educación terciaria el 35\% de sus gastos en educación, Turquía también el 35\%, y Egipto el 33\%. Esos países gastan mucho en educación terciaria, pero sus universidades no destacan. En cambio, el gasto público de República de Corea es solamente el $8 \%$, coincidiendo con un desarrollo económico considerable del país en los últimos años. Las diferencias se deben probablemente al número de estudiantes en educación terciaria y al nivel de privatización del sector de la educación terciaria. Así se explica, por ejemplo, que en Japón el gasto del sector público en educación terciaria sea solamente del 12\% —uno de los más bajos de los países desarrollados del mundo-, ya que la mayoría de sus universidades son privadas (73\%). 
En el mundo los gastos en educación — totales y del sector público— presentan bastante variabilidad, y no se observa una pauta convergente. La sorpresa es que no hay grandes diferencias entre los países desarrollados y los no-desarrollados en cuanto a la proporción del gasto. La situación en Europa parece más convergente. En ese contexto, España mantiene una inversión de recursos (totales y públicos) en educación excesivamente baja. La política española futura debería incluir estas tres medidas: a) incrementar el gasto en educación en relación con el PNB, aproximadamente un 20\%; b) aumentar algo más el gasto del sector público, entre el 20 y el $30 \%$; y c) aumentar mucho el gasto público en educación terciaria, aproximadamente un $50 \%$ de incremento. Dado que los recursos son escasos, la solución provisional sería reducir el gasto público relativo en educación secundaria y aumentar algo el de primaria. Idealmente deberían aumentar los tres, pero proporcionalmente más los recursos públicos en educación terciaria.

El gasto en educación debe ser entendido en relación con el número de estudiantes y con el ciclo de estudios que realizan, dado que el gasto no es el mismo en primaria que en secundaria o terciaria. La tabla 10 presenta algunos datos sobre gasto anual por estudiante según el nivel de estudios para países desarrollados (que son los que tienen estadísticas fiables). El coste medio es bastante diferente. Globalmente, un/a estudiante de secun-

TABLA 10

Gasto anual por estudiante según el nivel de estudios, en 1997

(En dólares USA)

\begin{tabular}{lccr} 
Países & Primaria & Secundaria & Terciaria \\
\hline Total OCDE & 3.769 & 5.507 & 10.893 \\
& & & 5.917 \\
Japón & 5.202 & 7.230 & 10.157 \\
Estados Unidos & 5.718 & 5.570 & 17.466 \\
Australia & 3.633 & & 11.240 \\
& & 6.149 & 9.466 \\
Alemania & 3.490 & 6.564 & 7.177 \\
Francia & 3.621 & 4.609 & 8.169 \\
Reino Unido & 3.206 & 6.284 & 5.972 \\
& & & 5.166 \\
Italia & 5.073 & 4.274 & $\ldots$ \\
España & 3.180 & 4.264 & 47 \\
Portugal & 3.248 & & 78 \\
Porcentaje de España respecto OCDE & & &
\end{tabular}

FUENTE:

OECD, Education At a Glance (París: OECD, 2000), p. 94. 
daria cuesta un $46 \%$ más que uno de primaria. En educación terciaria un estudiante cuesta tres veces más que en primaria, y casi el doble que en secundaria. La tendencia que se observa es que el gasto es mayor en los países más ricos. La máxima es siempre Estados Unidos, país rico pero que además dedica muchos recursos al sector educativo. En Japón - país que tiene el PNB per capita más alto que Estados Unidos- el gasto por estudiante en primaria es el $91 \%$ del gasto en Estados Unidos, en secundaria el $82 \%$, y en terciaria solamente el $58 \%$. Llama la atención el escaso presupuesto por estudiante universitario al año en Japón. Si se comparan los países de la OCDE, se observa que los recursos varían poco en educación obligatoria pero mucho en educación terciaria, donde el modelo de organización no es convergente. En primaria la variabilidad es 1,8 veces, en secundaria es la misma (1,7 veces), pero en terciaria la variabilidad entre países se eleva a 3,4 veces.

España gasta poco en educación; es una conclusión que deriva de las tablas que se analizan. En relación con la media de la OCDE, la desproporción es considerable. España en muchos otros indicadores económicos y sociales se ajusta bastante a la media de la OCDE. Pero hay que tener en cuenta que España tiene muchos estudiantes, sobre todo en educación terciaria. Si se mide el gasto por estudiante en primaria, España tiene un gasto que es el $84 \%$ de la media de la OCDE. En secundaria es el $78 \%$. Las diferencias son mayores en terciaria: el gasto real por estudiante al año en España es solamente el $47 \%$ de la media de los países de la OCDE. Hay que tener en cuenta que la mayor parte de las universidades en España son públicas, y que hay muchos estudiantes. La desproporción de recursos en educación terciaria (por estudiante) con Estados Unidos es enorme: España gasta tres veces menos recursos por estudiante al año. Todo indica que el gasto en educación terciaria en España debería por duplicarse.

En los países avanzados la educación es un gasto fundamentalmente público (85\% de media). La educación terciaria lo es en menor medida, pero todavía una responsabilidad mayoritariamente pública (77\%). La tendencia es que los países más desarrollados privatizan algo la educación: el sector privado de educación tiende a ser el $25 \%$, y en educación terciaria alcanzar incluso el 50\%. En la tabla 11 se puede ver la distribución del gasto público y privado en educación según niveles para algunos países escogidos de la OCDE. Se observa una tendencia hacia la privatización, o al menos a la expansión del gasto privado en educación, sobre todo a nivel terciario. España se ajusta casi exactamente a la media de la OCDE, aunque con un gasto privado ligeramente superior. Es preciso llamar la atención sobre el hecho de que el gasto privado en España es «superior» a la media, pues la opinión pública es la contraria. En todo el sistema educativo el sector privado representa el $15 \%$ del gasto en los países de la OCDE, pero es el 17\% en España. En cuanto a educación terciaria, el gasto privado de la OCDE es el $23 \%$, pero sube al $25 \%$ en el caso de España. 
TABLA 11

Distribución del gasto público y privado en educación según niveles, en 1997

(En porcentajes)

\begin{tabular}{|c|c|c|c|c|c|c|}
\hline \multirow[b]{2}{*}{ Países } & \multicolumn{2}{|c|}{ Total educación } & \multicolumn{2}{|c|}{ Primaria y secundaria } & \multicolumn{2}{|r|}{ Terciaria } \\
\hline & Público & Privado & Público & Privado & Público & Privado \\
\hline Media de países OCDE & 85 & 15 & 90 & 10 & 77 & 23 \\
\hline Japón & 76 & 24 & 92 & 8 & 45 & 55 \\
\hline Estados Unidos & 75 & 25 & 91 & 9 & 51 & 49 \\
\hline Australia & 77 & 23 & 86 & 14 & 58 & 42 \\
\hline Alemania & 79 & 21 & 76 & 24 & 92 & 8 \\
\hline Francia & 92 & 8 & 93 & 7 & 85 & 15 \\
\hline Reino Unido & $\ldots$ & $\ldots$ & $\ldots$ & $\ldots$ & 73 & 27 \\
\hline Italia & 96 & 4 & 100 & - & 76 & 24 \\
\hline España & 83 & 17 & 88 & 12 & 75 & 25 \\
\hline Portugal & $\ldots$ & $\ldots$ & $\ldots$ & $\ldots$ & 92 & 2 \\
\hline
\end{tabular}

NotA:

Son recursos después de transferencias.

FUENTE:

OECD, Education At a Glance (París: OECD, 2000), p. 67.

En el futuro, si España sigue el modelo de los países más desarrollados, es posible que el sector privado en educación aumente del 17 al 25\%, y en educación terciaria del 25 al $50 \%$. Se observa, pues, que el cambio predecible no es tanto en educación general como en educación terciaria, que puede privatizarse en mayor medida. La Unión Europea parece estar conteniendo ese proceso de privatización y consiguiendo que el gasto privado en educación terciaria sea $25 \%$, similar al que ya tiene España en estos momentos. No está claro lo que va a ocurrir, aunque es posible que se produzca —no sólo en España, sino en toda Europa - un proceso de privatización adicional del sector universitario. No sería súbito, permitiendo conocer la tendencia con varios años de antelación. No se prevé que sea una expansión del sector for profit, sino más bien el de universidades privadas sin ánimo de lucro. La distribución del gasto en España se ajusta a la media. El gasto en educación, y sobre todo en educación terciaria, en España es escaso, pero la distribución del gasto público/privado está equilibrada. No se trata, pues, de variar mucho la distribución del gasto como de expandir la cantidad total de recursos que en España se dedican a educación terciaria. 
Dentro del gasto público se puede considerar la distribución según los niveles de la Administración: central, regional, local. Esta distribución del gasto público en educación terciaria es variable en el mundo. Lo importante no es tanto de dónde provienen los recursos, sino su montante y cómo se distribuyen. La tabla 12 presenta algunos datos sobre los gastos en educación terciaria, por niveles de la Administración Pública, en países de la OCDE. En educación terciaria, la media muestra un modelo de centralización evidente, con un $76 \%$ del gasto proveniente de la Administración central, un $20 \%$ de la regional y un $4 \%$ de la local. Pero este modelo «medio» varía mucho. Hay países con un gasto en educación terciaria muy centralizado, como Italia (93\%), Australia (92\%) o Francia (91\%). Otro grupo de países -entre los que está España - sigue un modelo regionalizado, también denominado «descentralizado»: Alemania (86\%), España (80\%) y, en menor medida pero mayoritariamente, Estados Unidos (52\%). No hay países descentralizados a nivel de la Administración local, aunque Reino Unido destaca con un $23 \%$ del gasto en educación terciaria a ese nivel. España tiene un modelo universitario descentralizado por regiones (diecisiete Comunidades Autónomas), similar a la distribución del gasto en Alemania. El gasto de la Administración central en ambos países es menos de la quinta parte. Hay que tener en cuenta

TABLA 12

Gastos en educación terciaria, por niveles de la Administración Pública, en 1997

(En porcentajes)

Administración Pública

\begin{tabular}{|c|c|c|c|}
\hline \multirow[b]{2}{*}{ Países } & \\
\hline & Central & Regional & Local \\
\hline Media países OCDE & 76 & 20 & 4 \\
\hline Japón & 80 & 20 & - \\
\hline Estados Unidos & 39 & 52 & 11 \\
\hline Australia & 92 & 8 & - \\
\hline Alemania & 12 & 86 & 4 \\
\hline Francia & 91 & 5 & 4 \\
\hline Reino Unido & 77 & - & 23 \\
\hline Italia & 93 & 6 & \\
\hline España & 19 & 80 & \\
\hline Portugal & $\ldots$ & $\ldots$ & \\
\hline
\end{tabular}

NOTA:

Después de transferencias entre los niveles del Estado.

FUENTE:

OECD, Education At a Glance (París: OECD, 2000), p. 113. 
que en España el gasto de la Administración local es mínimo (1\%). No se puede afirmar que un modelo centralizado o descentralizado del gasto sea mejor; depende, lógicamente, de la política de cada país. España en ese contexto de modelo descentralizado parece equilibrada.

Los datos sobre la ayuda económica del Estado a los/as estudiantes son (desgraciadamente) escasos y difícilmente comparables. La tabla 13 presenta los mejores datos comparativos que existen sobre ayuda económica del Estado a estudiantes de educación terciaria. En los países desarrollados (OCDE), una quinta parte del gasto público en educación terciaria se destina a ayudar económicamente a los/as estudiantes. En España la proporción es la mitad de esa proporción (sólo el 10\%). Los países anglosajones destacan por tener el gasto más elevado en ayudas a estudiantes. En esos países los estudiantes universitarios son más independientes de sus familias, entre otras cosas porque existen ayudas económicas. La cantidad de dinero por estudiante al año no debe entenderse como becamedia, pues incluye a todos los estudiantes (con y sin ayuda). En esa cantidad-resumen de ayuda económica del Estado a estudiantes universitarios, España tiene 5,4 veces menos

Ayuda económica del Estado a estudiantes de educación terciaria, en 1997

\begin{tabular}{|c|c|c|c|}
\hline \multirow[b]{2}{*}{ Países } & \multirow[b]{2}{*}{$\begin{array}{r}\text { Como porcentaje } \\
\text { del gasto público } \\
\text { en educación terciaria }\end{array}$} & \multicolumn{2}{|c|}{ Ayuda del sector público, por estudiante al año } \\
\hline & & En dólares USA & $\begin{array}{r}\text { Porcentaje } \\
\text { de la ayuda } \\
\text { en préstamos }\end{array}$ \\
\hline Media países OCDE & 20 & 1.856 & 35 \\
\hline Japón & $\ldots$ & $\ldots$ & $\ldots$ \\
\hline Estados Unidos & 16 & 1.599 & $\ldots$ \\
\hline Australia & 26 & 1.478 & 45 \\
\hline Alemania & 11 & 1.090 & 22 \\
\hline Francia & 8 & 553 & $\ldots$ \\
\hline Reino Unido & 35 & 2.505 & 25 \\
\hline Italia & 13 & $\ldots$ & $\ldots$ \\
\hline España & 10 & 341 & $\ldots$ \\
\hline Portugal & 4 & 187 & $\ldots$ \\
\hline
\end{tabular}


ayuda que la media de la OCDE. Eso supone que la ayuda económica del sector público a los/as estudiantes debería por lo menos quintuplicarse. Hay una tendencia creciente a que la ayuda no sea sólo en forma de becas, sino también de préstamos. La media de la OCDE de la ayuda económica del sector público es de un 35\% en forma de préstamos a estudiantes. En España dicha modalidad de préstamos es prácticamente inexistente. La ayuda económica a estudiantes es seguramente el aspecto más retrasado de la educación terciaria en España, junto con los recursos para investigación universitaria.

\section{RECURSOS DE I+D}

Dos objetivos básicos de las organizaciones educativas del nivel terciario son la investigación y la formación de investigadores, incluyendo el doctorado. Investigación y desarrollo $(I+D)$ es un sector creciente, que concentra cada vez más recursos. Es también un sector que impulsa el desarrollo de un país. El factor de I+D es poco importante en cuanto al presupuesto del sector terciario, pero es esencial en cuanto al gasto o su ejecución. Por decirlo más claramente: el dinero suele venir de fuera de la Universidad, pero una mayoría de investigadores trabajan dentro de la Universidad. En I+D actualmente se observa en todo el mundo una disociación entre presupuesto y gasto, que no resulta disfuncional. En la tabla 14 se presentan los indicadores de investigación y desarrollo (I+D) en los países del mundo. El gasto nacional en I+D no proviene de las universidades. El presupuesto de I+D en educación terciaria representa entre el 0 y el 5\%, salvo casos raros (Israel, Canadá, México). Pero la investigación básica se realiza fundamentalmente dentro de las instituciones de educación terciaria, sobre todo en las llamadas «universidades-investigadoras».

La situación de la Unión Europea es buena. En Estados Unidos, con 268 millones de habitantes, hay 0,96 millones de personal en I+D, es decir, 3.593 personas por millón de habitantes. La Unión Europea (con 371 millones de habitantes) es un 38\% más populosa que Estados Unidos y tiene 1,6 millones de personal en I+D, lo que supone 4.313 personas por millón de habitantes. Es decir, que la Unión Europea tiene un 20\% más de personas de investigación que Estados Unidos. Sin embargo, las universidades-investigadoras de Estados Unidos son dominantes. La Federación de Rusia (con 147 millones de habitantes, la mitad que Estados Unidos) tiene más personal de I+D (1,0 millones) que Estados Unidos, lo que supone 7.163 personas por millón de habitantes: el doble que Estados Unidos. Alemania tiene unos niveles muy similares a Estados Unidos: con 82 millones de habitantes, tiene 0,46 millones de personas en I+D, equivalente a 5.598 personas por millón de habitantes, una tasa prácticamente igual a Estados Unidos. Todas estas comparaciones son de personal de $I+D$, no sólo investigadores. 
TABLA 14

Indicadores de investigación y desarrollo (I+D), circa 1997

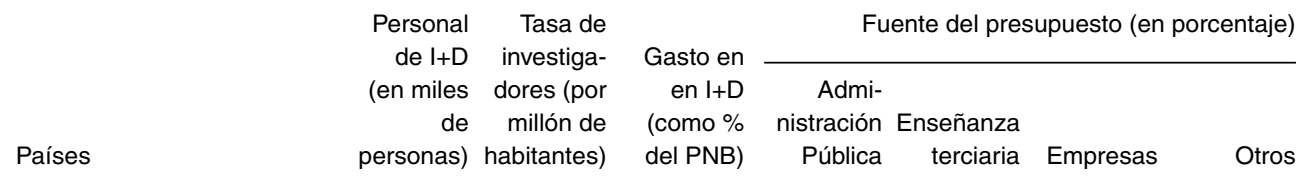

Países desarrollados:

Estados Unidos

Unión Europea (f):

Luxemburgo

Dinamarca

Austria

Alemania

Suecia

Bélgica

Países Bajos

Finlandia

Francia

Reino Unido

Italia

Irlanda

España

Grecia

Portugal

Europa del Este:

República Checa

Hungría

Polonia

Federación de Rusia

Otros desarrollados:

Japón
Australia
Canadá
Israel

Países en desarrollo:

Latinoamérica:

Argentina

México

Brasil

Venezuela
963 (a) $\quad 3.676$ (a) 2,63

\begin{tabular}{clr}
$\ldots$ & \multicolumn{1}{c}{$\cdots$} & $\cdots$ \\
32 & 3.259 & 1,95 \\
$24(\mathrm{a})$ & $1.627(\mathrm{a})$ & 1,53 \\
459 & 2.831 & 2,41
\end{tabular}

$63 \quad 3.826$

$38 \quad 2.272$

3,76

1,60

$81 \quad 2.219$

2,08

$34 \quad 2.799$

2,78

$321 \quad 2.659$

2,25

279 (a) 2.448

1,95

$142 \quad 1.318$

2,21

$12 \quad 2.319$

1,61

$89 \quad 1.305$

14 (a) 773 (a)

0,90

16

1.182

0,47 (a)

0,62

1,20

0,68

0,77

0,88

$\begin{array}{cll}892 & 4.909 & 2,80 \\ 90 & 3.357 & 1,80 \\ 130 & 2.719 & 1,66 \\ 27 \text { (b) } & 4.828 \text { (b) } & 2,35\end{array}$

0,38

0,33

0,81

0,49
36

5,1

59

38

48

37$$
5,0
$$

$$
0,4
$$$$
0,3
$$

$$
31
$$

\section{2,4}

0,9

2,6

0,4

1,4

3,7

$-$

0,9

1,0

3,7

3,9

$2030(\mathrm{e})$

46

65

$19 \quad 12(\mathrm{e})$

32

1,3

$$
4,0
$$

$63 \quad 3$

49

2,1

$36 \quad 10$

64

60

0,1

$32 \quad 2$

$16 \quad 25$

$\begin{array}{rrrl}18 & - & 82 & 0,1 \\ 48 & 4,2 & 46 & 2 \\ 30 & 8,4 & 51 & 11(\mathrm{e}) \\ 41 & 10,2 & 36 & 14\end{array}$


TABLA 14

Continuación

\begin{tabular}{|c|c|c|c|c|c|c|c|}
\hline \multirow[b]{2}{*}{ Países } & \multirow{2}{*}{$\begin{array}{r}\text { Personal } \\
\text { de I+D } \\
\text { (en miles } \\
\text { de } \\
\text { personas) }\end{array}$} & \multirow{2}{*}{$\begin{array}{r}\text { Tasa de } \\
\text { investiga- } \\
\text { dores (por } \\
\text { millón de } \\
\text { habitantes) }\end{array}$} & \multirow{2}{*}{$\begin{array}{r}\text { Gasto en } \\
\text { en I+D } \\
\text { (como \% } \\
\text { del PNB) }\end{array}$} & \multicolumn{4}{|c|}{ Fuente del presupuesto (en porcentaje) } \\
\hline & & & & $\begin{array}{r}\text { Admi- } \\
\text { nistración } \\
\text { Pública }\end{array}$ & $\begin{array}{r}\text { Enseñanza } \\
\text { terciaria }\end{array}$ & Empresas & Otros \\
\hline \multicolumn{8}{|l|}{ Asia: } \\
\hline República de Corea & 136 & 2.193 & 2,82 & 16 & - & 84 & - \\
\hline Turquía & 22 & 291 & 0,45 & 62 & 2,7 & 33 & 2 \\
\hline China & 787 & 454 & 0,66 & $\ldots$ & $\ldots$ & $\ldots$ & $\ldots$ \\
\hline India & 336 & 149 & 0,73 & 75 & 1,0 & 24 & - \\
\hline \multicolumn{8}{|l|}{ África: } \\
\hline Sudáfrica & $60(a)$ & $1.031(\mathrm{a})$ & $0,70(a)$ & 43 & 1,8 & 54 & 1 \\
\hline Argelia & $\ldots$ & $\ldots$ & $\ldots$ & $\ldots$ & $\ldots$ & $\ldots$ & $\ldots$ \\
\hline Egipto & $102(c)$ & 459 (c) & 0,22 & $\ldots$ & $\ldots$ & $\ldots$ & $\ldots$ \\
\hline Marruecos & $\ldots$ & $\ldots$ & $\ldots$ & $\ldots$ & $\cdots$ & $\ldots$ & $\cdots$ \\
\hline \multicolumn{8}{|l|}{ Países menos desarrollados: } \\
\hline Tanzania (República Unida de & e) & $\ldots$ & $\ldots$ & $\ldots$ & $\ldots$ & $\ldots$ & $\ldots$ \\
\hline Mozambique (c) & $\ldots$ & $\ldots$ & $\ldots$ & $\ldots$ & $\ldots$ & $\ldots$ & $\ldots$ \\
\hline Níger & $\ldots$ & $\ldots$ & $\ldots$ & $\ldots$ & $\ldots$ & $\ldots$ & $\ldots$ \\
\hline Etiopía & $\ldots$ & $\ldots$ & $\ldots$ & $\ldots$ & $\ldots$ & $\ldots$ & $\ldots$ \\
\hline
\end{tabular}

NOTAS:

I+D se refiere a «investigación y desarrollo».
(a) En 1993.
(b) En 1984
(c) En 1991.
(d) En 1992.
(e) Son fondos del extranjero.
(f) La Unión Europea tiene aproximadamente 1,6 millones de personal de I+D. Estados Unidos supone el 60\% de esa canti- dad.

FUENTE:

UNESCO, Statistical Yearbook 1999 (París: Unesco Publishing \& Bernan Press, 1999), II, pp. 6-35.

En los países desarrollados las diferencias en el número de investigadores son grandes. Oscilan entre mil y cinco mil por cada millón de habitantes, una diferencia real de 4,5 veces. Japón tiene la tasa de investigadores más alta del mundo, con 4.909 investigadores por millón de habitantes. Es un tercio más que en Estados Unidos y cuatro veces más que en España. En el contexto de países desarrollados, la situación de investigadores en España supone un nivel bajo. Con 1,3 investigadores por cien mil habitantes, España tiene la tercera parte de los que debería tener. El ideal sería al menos tres o cuatro investigadores 
por cien mil habitantes. Para lograrlo, España necesita un incremento de dos y media a tres veces más investigadores. Eso supondría, además, un esfuerzo enorme de formación (doctorado) en las universidades.

Los países desarrollados gastan entre el 2 y el 3\% de su PNB en investigación. En España no llega al 1\%. Debería, pues, multiplicarse por dos o por tres, por lo menos. Pero hay que tener en cuenta que las diferencias de gasto en I+D sobre el PNB oscilan bastante, entre el 0,6 y el $2,8 \%$, es decir, 4,5 veces. Es una variación similar a la tasa de investigadores. El gasto en I+D y la tasa de investigadores varían de forma similar, lo que es congruente. Lo que caracteriza a los países «en desarrollo» es que casi ninguno llega a mil investigadores por millón de habitantes. La excepción es República de Corea, con 2.193 investigadores por millón de habitantes. Los países no-desarrollados dedican menos del $1 \%$ del gasto del PNB a I+D. No investigan porque no son desarrollados, y viceversa. En realidad, como se puede observar en la tabla, los países más pobres ni siquiera tienen estadísticas de I+D. El nivel de subdesarrollo se hace patente en la falta de datos.

Los países de Europa meridional —Portugal, España, Italia, Grecia- destacan porque el gasto de la Administración Pública en I+D es mayor que el de las empresas. En el resto de la Unión Europea, Estados Unidos y Japón ocurre lo contrario. Japón es el caso más claro de inversión de las empresas en el ámbito de la investigación, representando el $82 \%$ del presupuesto nacional de I+D. Así se explica la tasa alta de investigadores. Es también un caso claro de éxito investigador. España, con un $40 \%$ del presupuesto de investigación procedente de las empresas, debería incrementar mucho esa proporción. En los países «en desarrollo» la parte del presupuesto proviniente de las empresas en I+D apenas tiene importancia.

La participación del sector educativo terciario en el presupuesto de I+D es simbólica. Las universidades de los países desarrollados invierten entre un 0,1 y un $5 \%$ en el presupuesto nacional de I+D; los países «en desarrollo» invierten entre el 0,6 y el $8 \%$. No hay apenas diferencias en las proporciones, y las variaciones no son difícilmente explicables. Tampoco indican un sistema mejor o peor. Lo importante es la investigación final, no tanto quién la paga. El papel de la Universidad en el presupuesto de I+D es mínimo. La importancia del sector público parece ser cada vez menor. Se está produciendo un proceso de privatización de I+D en cuanto a la fuente de financiación. Pero la Universidad (muchas veces pública) continúa siendo un elemento fundamental en la investigación básica y en la formación de investigadores.

La situación de España es deficitaria en I+D. Necesitaría lograr tres objetivos: a) el gasto en I+D como proporción del PNB necesitaría multiplicarse por dos o por tres veces, hasta 
alcanzar el 2,5\%; b) el número de investigadores debe también duplicarse o triplicarse, para alcanzar entre 2.500 y 3.000 investigadores por millón de habitantes; y c) las proporciones del presupuesto de la Administración Pública (52\%) y empresas (40\%) deberían invertirse; al mismo tiempo que la proporción del presupuesto de I+D proveniente del sector de educación terciaria debería duplicarse o triplicarse. Sólo así podría España superar su situación deficitaria, que es desequilibrada en relación con el resto de indicadores de desarrollo e incluso de educación terciaria.

\section{PAPEL CENTRAL DE LAS BIBLIOTECAS}

Un recurso esencial en la educación terciaria, así como en la formación de investigadores, son las bibliotecas. La Universidad gira en torno a la biblioteca. La tabla 15 presenta datos de bibliotecas en países distintos. Incluye datos específicos sobre bibliotecas universitarias $^{10}$. Los «libros de bibliotecas» combinan tres tipos: bibliotecas nacionales, todo tipo de bibliotecas públicas (no escolares) y las universitarias. Juntando los tres tipos de bibliotecas, el mundo desarrollado tiene entre 1 y 10 libros por habitante. Los países con más libros son Rusia y los escandinavos. Los países desarrollados con menos libros son España y Portugal. Se observa una pauta norte/sur: el norte de Europa con las tasas más altas de libros por habitante, y Europa meridional con las tasas más bajas. En ese contexto, Europa del Este está bastante bien dotada de libros, sobre todo la Federación de Rusia, que alcanza la cifra de 9,4 libros por habitante (sólo por detrás de Finlandia, que tiene 10,6). La sorpresa es que países centrales - que juegan un papel importante en el pensamiento y la investigación occidentales- no tienen muchos libros: Reino Unido, 4,3 libros por habitante; Alemania, 3,6, y Francia, 2,1. El caso de Francia es llamativo. Otra sorpresa es Japón, cuyas bibliotecas sólo tienen tres libros por habitante. Para los países «en desarrollo» no hay datos, o son poco fiables, pero en cualquier caso no llegan a un libro por habitante.

El número de libros por habitante es un indicador que debe matizarse. Un país, aunque sea pequeño, necesita un mínimo de libros accesibles a la comunidad investigadora en las diversas áreas de conocimiento, independientemente del número de habitantes de ese país. Se supone que veinte millones de libros por país es una cantidad mínima. La realidad es que ese número absoluto varía mucho, y sigue estando en relación con el tamaño del país. Es el caso de China, con 735 millones de libros, o de Rusia, con 1.384 millones de libros. Países grandes y poderosos tienen un volumen total (en números absolutos) apreciable de libros: Alemania, Reino Unido, Francia, Japón. Otros países de Europa del Este con bastante población y tradición intelectual —como Polonia — tienen también bastantes li-

\footnotetext{
10 Desgraciadamente, los datos de la UNESCO no incluyen a Estados Unidos.
} 


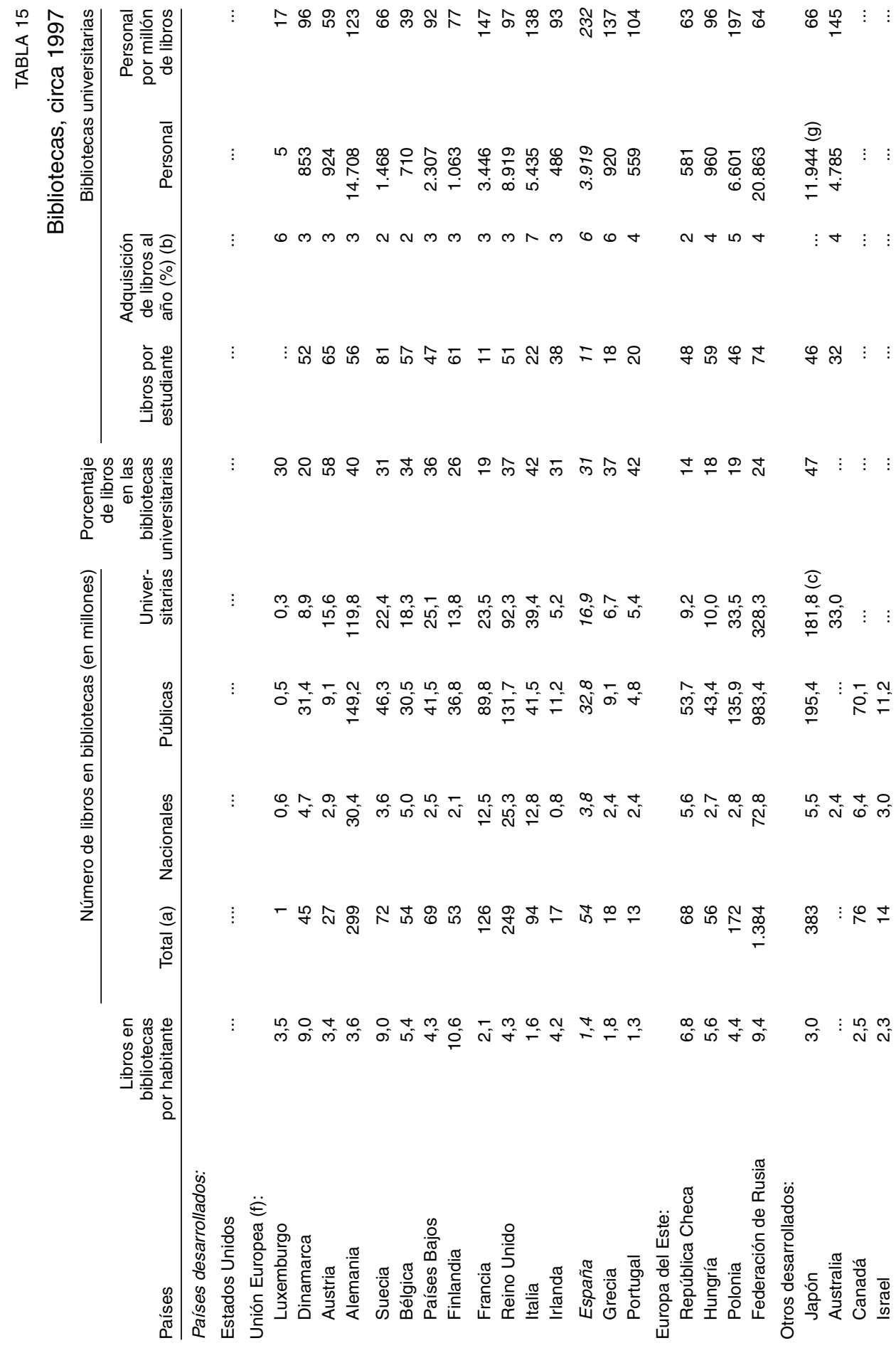




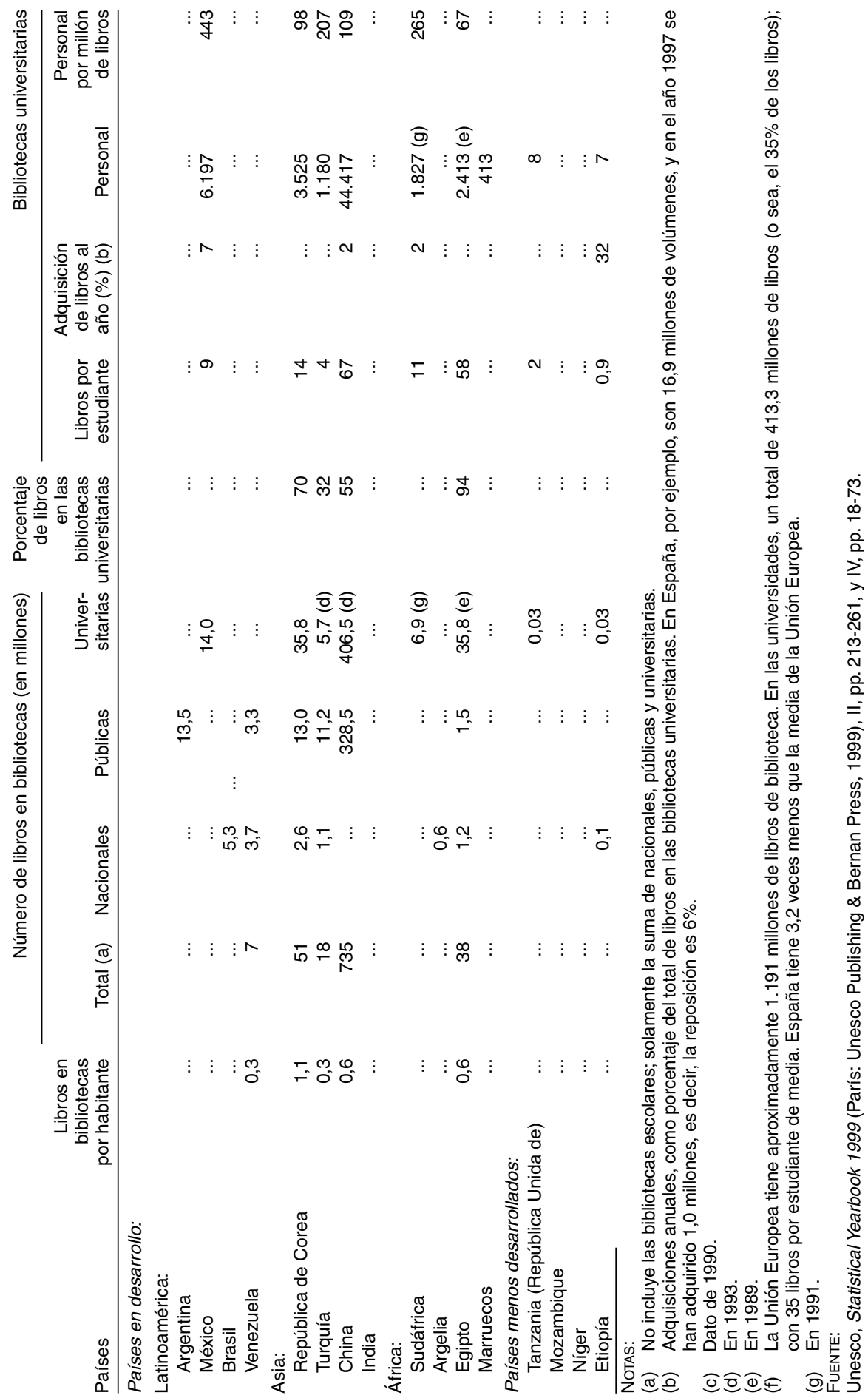


bros. Polonia tiene la misma población que España (39 millones de habitantes) pero 3,2 veces más libros en sus bibliotecas. Los países desarrollados, aunque sean pequeños, superan casi todos los veinte millones de libros. Se supone que es una cantidad mínima, como lo es la de dos millones de libros para la biblioteca de una universidad-investigadora. En Europa, Portugal sólo alcanza a tener 13 millones, y Grecia e Irlanda quedan un poco por debajo del listón de los veinte millones de libros.

Hay un cierto equilibrio entre las bibliotecas de las universidades y el resto de bibliotecas (nacionales y públicas) del país. El volumen de libros de las bibliotecas universitarias suele ser algo más de un tercio. En la Unión Europea la media es de un 35\% de libros en bibliotecas universitarias. España tiene sólo un 31\%, lo que indica que sus universidades están un poco por debajo de lo debido. Teniendo en cuenta que, además, España tiene la cantidad mínima de libros de todo el mundo desarrollado (junto con Portugal), el que las universidades tengan un porcentaje inferior a la media resulta negativo. Pero la proporción de libros universitarios no es un factor totalmente condicionante. Hay dos modelos universitarios: Alemania, con una importancia grande de las bibliotecas universitarias (40\% de los libros), y Francia, con una importancia pequeña de sus bibliotecas universitarias (19\%). España o el Reino Unido se sitúan entre ambos modelos. En los países asiáticos más desarrollados la proporción de libros en las universidades es mucho más alta: $47 \%$ en Japón y 70\% en República de Corea. En los países «en desarrollo» (pero no desarrollados) la importancia proporcional de las bibliotecas universitarias es elevada. Pero no así en Europa del Este, en donde las bibliotecas universitarias contienen en torno al $20 \%$ de los libros del país; en Rusia es el $24 \%$.

Estos factores diversos explican que el número de libros por estudiante en educación terciaria sea bastante diferente entre países. En el mundo desarrollado varía entre 11 y 81 libros por estudiante, es decir, más de siete veces de diferencia. Se vuelve a observar una pauta norte/sur: la máxima de libros en universidades (por estudiante) está en Suecia; Rusia tiene una tasa elevada. La mínima es España, puesto que comparte con Francia. Japón - a pesar de su desarrollo- está situada en un punto medio bajo (46 libros por estudiante universitario). En los países no-desarrollados, las diferencias entre países son enormes, desde menos de un libro por estudiante a 67 libros: 74 veces de diferencia. La máxima es China, con 67 libros por estudiante, que es una cantidad apreciable. La situación de Europa meridional es lamentable, especialmente la de España, que es la mínima de todos los países desarrollados ${ }^{11}$. Lo único positivo del sur de Europa es que está adquiriendo libros -lo que se llama tasa de reposición- a bastante más velocidad que el resto de Europa,

11 En el año 2000 se eleva a 16 libros por estudiante universitario, todavía un nivel bajo. Pero la tasa de reposición baja a $4,7 \%$. 
aproximadamente al doble de velocidad. España adquiere libros al ritmo del $6 \%$ anual, teniendo la tasa máxima de reposición en Europa, junto con Italia (7\%). A pesar de esa velocidad de reposición, España va a tardar años en resolver la situación precaria de sus bibliotecas universitarias. Según las estadísticas oficiales (del Estado español, enviadas a UNESCO), las universidades españolas tienen 17 millones de volúmenes en sus bibliotecas (datos para 1997). Eso supone una media de 313.000 libros por universidad, una cantidad irrisoria para ser consideradas como universidades-investigadoras ${ }^{12}$. El tamaño mínimo de las bibliotecas debe ser dos millones de volúmenes por universidad, independiente del tamaño de la universidad. Llegar a ese nivel supondría multiplicar por seis el número de libros de las bibliotecas universitarias españolas; algo difícil de conseguir en un futuro próximo ${ }^{13}$.

Las estadísticas de personal de bibliotecas universitarias son algo peculiares, pues varían de forma errática. Por cada millón de libros, las bibliotecas universitarias de los países desarrollados tienen entre 39 y 232 personas trabajando en la biblioteca. Es una diferencia de seis veces. La sorpresa es que hay más personal cuanto peor equipadas están las bibliotecas universitarias. España, Francia e Italia tienen las bibliotecas universitarias mejor dotadas de personal, pero con un menor número de libros. La máxima de personal -232 personas por cada millón de libros- corresponde a España ${ }^{14}$. Las universidades españolas tienen el raro privilegio de ser las que tienen menos libros pero más personal de biblioteca. Los países no-desarrollados apenas tiene estadísticas de personal; los países que presentan datos oscilan entre 67 y 443 personas por cada millón de libros de biblioteca universitaria. Es una variación de siete veces. La tasa máxima de personal de biblioteca corresponde a México.

Esos datos —enviados oficialmente por cada país y contrastados por la UNESCO_ suponen una realidad problemática en el caso de España. Es el país con menos libros y con más personal bibliotecario en su sistema de educación terciaria. Las universidades españolas tienen pocos libros, apenas 11 por estudiante universitario. Esas universidades están peor dotadas de libros que el conjunto del país, que es uno de los que menos libros tiene en todo el mundo desarrollado (es el segundo por la cola, tras Portugal). Sería necesario

12 En el año 2000 son ya 26,6 millones de volúmenes, pero ha aumentado el número de universidades. La media es de 451.000 libros, para una universidad media de 27.600 estudiantes.

${ }^{13}$ Los datos de bibliotecas universitarias deparan sorpresas. Francia, por ejemplo, tiene una situación carencial considerable, con 11 libros por estudiante universitario, igual que España. Pero, además, tiene una de las tasas de reposición más bajas: 3\% anual. En comparación con el resto de las bibliotecas francesas, las bibliotecas universitarias del país galo son las menos importantes de Europa, con apenas un 19\% de los libros del país (cuando la media de la Unión Europea es del 35\%). El problema, pues, no es solamente de España, sino de todo el sur de Europa.

14 En el año 2000 se reduce a 181 personas por millón de libros; todavía una cantidad elevada. 
multiplicar esa cantidad al menos por cinco para llegar a un nivel medio aceptable. El objetivo debe ser al menos de 50 libros por estudiante de universidad ${ }^{15}$. España debe, además, aumentar la importancia de las bibliotecas universitarias en el contexto nacional. Debería elevar la proporción de libros en bibliotecas universitarias del 31 al $40 \%$ del total de bibliotecas en el país. Hay que tener en cuenta que la situación es deficitaria también en otros ámbitos. La reposición del $6 \%$ anual en las bibliotecas universitarias españolas está bien y debería mantenerse, pero en realidad disminuye a menos del $5 \%$. Aunque con esa proporción no va a ser fácil pasar de la media de 313.000 libros por universidad a dos millones mínimo que necesita una institución terciaria investigadora en la actualidad. Además de ese esfuerzo en las universidades, España necesita duplicar o triplicar el número de libros en las bibliotecas públicas y tener una Biblioteca Nacional mucho mejor dotada. De 1,4 libros por habitante en total debe pasar por lo menos a 5,0 lo antes posible. Que en «bibliotecas nacionales» España sólo tenga 3,8 millones de libros es una cantidad demasiado baja. En bibliotecas nacionales, Reino Unido tiene 25 millones; Alemania, 30, y Rusia, 73. Incluso Francia tiene el triple de volúmenes que España. La Universidad española no puede desarrollarse si no plantea una política bibliotecaria decidida, en un contexto en el que el objetivo sea duplicar o triplicar los recursos para sus universidades. Estos recursos no dependen tanto de estudiantes o de profesores como del volumen general de investigación en el país. La investigación en España es tres veces menor de lo esperable para el nivel de desarrollo del país, pero los recursos destinados a sus bibliotecas son cinco veces menos de lo que debieran, similar a la necesidad de más investigación.

\section{BIBLIOGRAFÍA}

«Almanac 2002-3», The Chronicle of Higher Education, vol. 49, n. ${ }^{\circ} 1$ (30 agosto 2002), 96 pp. Número extraordinario
sobre «Facts about higher education in the U.S., each of the 50 States, and D.C.». Anuario de la educación terciaria
en Estados Unidos, incluyendo datos por Estados, y la encuesta a estudiantes de primero de carrera.

ALMARCHA, Amparo: Autoridad y privilegio en la Universidad española: Estudio sociológico del profesorado universitario (Madrid: Centro de Investigaciones Sociológicas, 1982), 376 pp. Es una encuesta a 594 profesores universitarios en cuatro universidades públicas españolas (Córdoba, Granada, Sevilla y Valladolid) en la primavera de 1980.

ASSOCIATION OF RESEARCH LIBRARIES: «Holdings of university research libraries in U.S. and Canada, 2000-1", The Chronicle of Higher Education, vol. 48, n. 48 (9 agosto 2002), p. A18. Con datos de 113 universidades norteamericanas, incluye un índice de ranking. Más información en www.arl.org.

BANCO INTERAMERICANO DE DESARROLLO: La educación superior en América Latina y el Caribe: Documento de estrategia (Washington DC: BID, Departamento de Desarrollo Sostenible, Unidad de Educación, 1997), 53 pp. Es la publicación EDU-101. Información adicional en www.iadb.org/sds/edu.

15 Contrario a lo que se supone, sobra personal de biblioteca. Si los datos son exactos, habría que decrecer su número a un tercio. Hay actualmente en las bibliotecas universitarias españolas 232 personas por millón de libros; sería suficiente con 100. No es posible asegurar la fiabilidad de estos datos. 
BARÓ, Ezequiel, et al.: Informe Universidad 2000 (Madrid: Conferencia de Rectores Universitarios Españoles, 2000), 484 pp. Informe encargado por los rectores españoles previo a la LOU, que no llegó a plantearse como reforma efectiva. También se conoce como «Informe Bricall», por uno de sus autores.

BELLAVISTA, Joan; TURPIN, Tim; HILL, Stephen, y MIGUEL, Jesús M. de: «Cultura organizativa de investigadores y entorno político y social», Papers. Revista de Sociología, 54 (1998), pp. 79-109.

«Best Graduate Schools: 2002 Edition», U. S. News and World Report (2002), 195 pp. Plus a directory of Business, Education, Engineering, Law, and Medical Schools. Información adicional en www.usnews.com.

CAMí, Jordi, et al.: Un análisis de la política científica en España, número monográfico de la revista Quark: Ciencia, Medicina, Comunicación y Cultura, 22-23 (2002), 144 pp.

CARABAÑA, Julio: Educación, ocupación e ingresos en la España del siglo xx (Madrid: Ministerio de Educación y Ciencia, 1983).

— «El punto ciego de la Ley de Universidades», Claves de Razón Práctica, 119 (2002), pp. 32-41. Es una crítica de la práctica de la LRU y de las posibilidades de la LOU.

CARABAÑA, Julio, y ARANGO, Joaquín: «La demanda de educación universitaria en España 1960-2000», Revista Española de Investigaciones Sociológicas, 24 (1983), pp. 47-88.

CARNEGIE FOUNDATION FOR THE ADVANCEMENT OF TEACHING: A Classification of Institutions of Higher Education (Princeton: Carnegie Foundation for the Advancement of Teaching, 1994). Ver también en www.carnegiefoundation.org.

CASTILLO, Juan J.: «La Universidad real: Fuera de la ley», El País (8 octubre 2001), p. 44.

CASTILLO, Pilar del: «Problemas y perspectivas de la educación en España», Papeles de Economía Española, 86 (2000), pp. 310-314.

CELESTINO REY, Fernando: «Perspectivas futuras de los indicadores de la educación», en Instituto Nacional de Estadística, Indicadores sociales de España (Madrid: INE, 2001), 593 pp., pp. 543-593. Estudio excelente que diferencia los factores de contexto, recursos, funcionamiento y resultados. Pone en relación las tasas educativas y las de empleo.

CENTRE FOR EDUCATIONAL RESEARCH AND INNOVATION: Redefining Tertiary Education (París: OECD, 1998).

- Education Policy Analysis 1999 (París: OECD, 1999), 94 pp. Ver especialmente «Tertiary education: Extending the benefits of growth to new groups», pp. 65-84.

CENTRO DE INVESTIGACIÓN Y DOCUMENTACIÓN EDUCATIVA (CIDE): El sistema educativo español 1995 (Madrid: Ministerio de Educación y Ciencia, 1995), 343 pp. El capítulo 7, sobre «Educación universitaria», en las pp. 167177 y 286-303.

COBO, Juan M.: «Educación», en Fundación Foessa (ed.), Quinto informe sociológico sobre la situación social en España: Sociedad para todos en el año 2000 (Madrid: Fundación Foessa, 1994), pp. 1107-1276.

COMISIÓN INTERMINISTERIAL DE CIENCIA Y TECNOLOGÍA: Sistema español de ciencia y tecnología (Madrid: Ministerio de Educación y Ciencia, 1989), 32 pp. Hay una edición en inglés titulada The System of Science and Technology in Spain.

CONSEJO DE COORDINACIÓN UNIVERSITARIA: Estadística universitaria del curso 2001-2002 (Secretaría General del CCU, 2002), 93 pp.

CURRIE, Jan, y NEWSON, Janice (eds.): Universities and Globalization: Critical Perspectives (Thousands Oaks, California: Sage, 1998), $339 \mathrm{pp}$. 
CHARLES, Maria, y BRADLEY, Karen: «Equal but separate? A cross-national study of sex segregation in higher education», American Sociological Review, 67 (2002) pp. 573-599.

DIONNE, Joseph L., y KEAN, Thomas: Breaking the Social Contract: The Fiscal Crisis in Higher Education (Nueva York: Council for Aid to Education, 1997). Es un informe de la Comisión on National Investment in Higher Education.

DOLENCE, Michael G., y NORRIS, Donald M.: Transforming Higher Education: A Vision for Learning in the 21st Century (Ann Arbor, Michigan: Society for College and University Planning, 1995). Incluido en la serie de estudios publicados por la Society for College and University Planning en University of Michigan.

DUDERSTADT, James J.: A University For the 21st Century (Ann Arbor: The University of Michigan Press, 2000), 358 pp. Por el presidente de la Universidad de Michigan (Ann Arbor) durante una década.

DUNKERLEY, David, y WONG, Wai Sum (eds.): Global Perspectives on Quality in Higher Education (Burlington: Ashgate, 2001), $160 \mathrm{pp}$.

EMBID, Antonio, y MICHAVILA, Francisco: Hacia una nueva Universidad: Apuntes para un debate (Madrid: Tecnos, 2001), $118 \mathrm{pp}$.

«Especial LOU», Gaceta Universitaria (28 noviembre 2001). Es un número especial, de 16 pp., en www.tugued.com.

ESPING-ANDERSEN, Gosta: «La Universidad en la economía del conocimiento: Los nuevos retos de la política educativa española», Empresa y Finanzas (14 julio 2000).

EUROPEAN COMMISSION: The Economic and Financial Situation of Spain (Luxemburgo: DG for Economic and Financial Affairs, 1994). Es el número 7.

- Key Data On Education in Europe 1999-2000 (Luxemburgo: Office for the Official Publications of the European Communities, 2000).

- Towards a European Research Area: Science, Technology and Innovation. Key Figures 2000 (Luxemburgo: Office for the Official Publications of the European Communities, 2000).

FERNÁNDEZ ENGUITA, Mariano: «Educación superior», en Salustiano del Campo (ed.), Tendencias sociales en España 1960-1990 (Bilbao: Fundación BBV, 1993), vol. 3, pp. 359-380.

FUNDACIÓN FOESSA (ed.): Informe sociológico sobre la situación social de España 1970 (Madrid: Euramérica, 1970), 1.634 pp. Elaborado por Amando de Miguel. El capítulo 14, sobre «Educación y ciencia», está en las pp. 833 a 1050. El estudio más avanzado para su época, con una crítica de la Ley General de Educación.

FUNDACIÓN SANTANDER CENTRAL HISPANO (ed.): La Universidad en la sociedad del siglo XXI (Madrid: Fondo de Cultura Económica, 2001), 304 pp. Incluye las ponencias de siete rectores españoles y siete latinoamericanos en las «Jornadas sobre Iberoamérica y España», celebradas en la Casa de América (Madrid) en junio 2001. Véase la recensión en la Revista Española de Investigaciones Sociológicas, 99 (2002).

GARCÍA DE CORTÁZAR, Marisa, y GARCÍA DE LEÓN, María A.: Mujeres en minoría: Una investigación sociológica sobre las catedráticas de universidad en España (Madrid: Centro de Investigaciones Sociológicas, 1997), 88 pp. Número 16 de la Colección Opiniones y Actitudes. Primera encuesta a 245 mujeres-catedráticas de Universidad en 1995.

GARCÍA DE CORTÁZAR, Marisa; GARCÍA DE LEÓN, María A., y GÓMEZ ULLATE, Martín: «Postgraduate studies in Spain", European Journal of Education: Research, Development and Policies, vol. 3, n. ${ }^{\circ} 2$ (junio 1998). Es un número monográfico sobre Postgraduate Education in Europe.

GARCÍA DE LEÓN, M. ${ }^{a}$ Antonia, y GARCÍA DE CORTÁZAR, Marisa (eds.): Las académicas: Profesorado universitario y género (Madrid: Instituto de la Mujer, 2001), 623 pp. 
GENERALITAT DE CATALUNYA: «Llei d'Universitats de Catalunya», Butlletí Oficial del Parlament de Catalunya (febrero 2003).

GIAMATTI, A. Bartlett: A Free and Ordered Space: The Real World of the University (Nueva York: W. W. Norton, 1988). Por el presidente de Yale University.

GIDDENS, Anthony: Runaway World: How Globalisation is Reshaping our Lives (Londres: Profile Books, 1999), $104 \mathrm{pp}$.

GONZÁLEZ, Manuel J.: La Universidad del siglo xxI: Libertad, competencia y calidad (Madrid: Círculo de Empresarios, 1999), $144 \mathrm{pp}$.

HERNÁNDEZ ARMENTEROS, Juan: Información académica, productiva y financiera de las universidades públicas españolas. Año 2000: Indicadores universitarios (curso académico 2000-2001) (Madrid: CRUE, Conferencia de Rectores de Universidades Españolas, 2002), www.crue.org/cdOBSERVATORIO/index.htm, consultado el 3 de julio de 2002. Ver especialmente la tabla V.I.9. El autor es el gerente de la Universidad de Jaén.

HIRSCH, Werner Z., y WEBER, Luc E. (eds.): Governance in Higher Education: The University in a State of Flux (Washington DC: Brookings Institution Press, 2002).

HUISMAN, J.; MAASSEN, Peter, y NEAVE, Guy (eds.): Higher Education and the Nation State (Oxford: Pergamon Press, 2000).

IGLESIAS DE USSEL, Julio: «La LRU siete años después», Crítica, n. ${ }^{\circ} 779$ (1990), pp. 50-52, y n. ${ }^{\circ} 780$ (1990), pp. 53-55.

- «Una reflexión sobre la Universidad», en Proyectos para la Universidad española (Madrid: Anales de la Real Academia de Ciencias Morales y Políticas, 2001), año 53, n. ${ }^{\circ}$ 78, curso académico 2000-2001, pp. 469-483.

«Inside the knowledge factory: A survey of universities», The Economist (4 octubre 1997), 22 pp.

INSTITUTO NACIONAL DE ESTADÍSTICA: Estadística de la enseñanza superior en España: Curso 1996-1997. Series de todos los niveles (Madrid: INE, 1999), en publicación electrónica con un disquete. Existe la versión en papel con 339 pp. Son las estadísticas anuales más detalladas y oficiales sobre la enseñanza terciaria en España.

- Estadística de las pruebas de acceso a la Universidad 1998: Resultados detallados (Madrid: INE, 1999), 77 pp.

- Estadística sobre actividades en investigación científica y desarrollo tecnológico (I+D) 1997 (Madrid: INE, 1999), 238 pp. Existe también en disquete con información electrónica.

- Estadística de bibliotecas 1998 (Madrid: INE, 2000), 399 pp.

- Enseñanza universitaria de primer y segundo ciclo. Alumnado matriculado y su evolución: Curso 2000-2001 (Madrid: Instituto Nacional de Estadística, 2001), 48 pp.

— Indicadores sociales de España (Madrid: INE, 2001), 593 pp. Tiene una sección de estadísticas educativas.

- Estadística de las pruebas de acceso a la Universidad 2001 (Madrid: INE, 2002), 88 pp.

- Estadística sobre las actividades en investigación científica y desarrollo tecnológico (I+D): Indicadores básicos (Madrid: INE, 2002), $149 \mathrm{pp}$.

JENKS, Christopher, y RIESMAN, David: The Academic Revolution (Chicago: The University of Chicago Press, 1977), 580 pp. No se refiere a la revolución estudiantil de mayo 1968.

JOHNSON, Sandra L.; RUSH, Sean C., y COOPERS \& LYBRAND (eds.): Reinventing the University: Managing and Financing Institutions of Higher Education (Nueva York: John Wiley \& Sons, 1995), 401 pp. 
JONGBLOED, Ben; MAASSEN, Peter, y NEAVE, Guy: From the Eye of the Storm: Higher Education's Changing Institution (Dordrecht: Kluwer Academic Publishers, 1999).

KAGAN, Richard L.: Universidad y sociedad en la España moderna (Madrid: Tecnos, 1981).

KENNEDY, Donald: Academic Duty (Cambridge: Harvard University Press, 1997), 310 pp.

KERR, Clark: The Uses of the University (Cambridge, Mass.: Harvard University Press, 1963), 226 pp. Se utiliza la cuarta edición de 1995, con el prefacio nuevo, "A new context for higher education». Es interesante comparar el primer capítulo, "The idea of multiversity», de 1963 con el capítulo 8, "Hard choices», escrito tres décadas después.

- The Guardians: Board of Trustees of American Colleges and Universities. What They Do and How Well They Do It (Washington DC: Association of Governing Boards, 1989).

LATIESA, Margarita: Los jóvenes ante el sistema educativo (Madrid: Centro de Investigaciones Sociológicas, 1991), $234 \mathrm{pp}$.

- La deserción universitaria: Desarrollo de la escolaridad en la enseñanza superior. Éxitos y fracasos (Madrid: Centro de Investigaciones Sociológicas, 1992), 407 pp. Medida del rendimiento académico a través del abandono de carrera.

LOU 2001: «Ley Orgánica 6/2001, de 21 de diciembre, de Universidades», Boletín Oficial del Estado, 307 (24 diciembre 2001), pp. 49/400-49/425. El proyecto fue aprobado por el Pleno del Congreso de los Diputados en sesión celebrada el día 31 de octubre de 2001. La Ley final consta de 89 artículos, con una exposición de motivos, además de 27 disposiciones adicionales, ocho transitorias, una derogatoria y cinco finales. La LOU se aplica a partir del 13 enero 2002.

LRU 1983: «Ley Orgánica 11/1983, de 25 de agosto, de Reforma Universitaria», Boletín Oficial del Estado, 209 (1 septiembre 1983), pp. 24034-24042. La Ley consta de 59 artículos, con otras disposiciones.

MANZANARES, Pilar: «La CRUE no quiere que se puntúe a las universidades ni que se hagan rankings», Gaceta Universitaria, 307 (7 diciembre 2001), pp. 1-2.

MARAVALL, José M.: Dictatorship and Political Dissent: Workers and Students in Franco's Spain (Londres: Tavistock, 1978).

MARÍ-KLOSE, Marga, y NOS, Anna: Itinerarios vitales: Educación, trabajo y fecundidad de las mujeres (Madrid: Centro de Investigaciones Sociológicas, 1999), 123 pp., n. ${ }^{\circ} 27$ de la Colección Opiniones y Actitudes.

MARTÍN MORENO, Jaime, y MIGUEL, Amando de: Universidad, fábrica de parados: Informe sociológico sobre las necesidades de graduados universitarios en España y sus perspectivas de empleo (Barcelona: Vicens-Vives, 1979), 193 pp. Un libro que generó un debate extenso en los primeros años de la nueva democracia.

MAS-COLELL, Andreu: «La universitat catalana que volem», Avui (jueves 1 noviembre 2001), p. 24. Señala los cuatro aspectos mejores del proyecto de la LOU. Mas-Collel es conseller de Universidades, Investigación y Sociedad de la Información, en Cataluña.

— «Els camins europeus de Catalunya: La Universitat», conferencia en el Palau de la Generalitat (9 enero 2002), 16 pp. Se divide en: 1) Universidad y espacio europeo; 2) la calidad docente; 3) la universidad de investigación; 4) el profesorado universitario, y 5) los estudiantes. Es el discurso central de la reforma universitaria en la Comunidad Autónoma de Cataluña. Una referencia aparece en «Mas-Colell defiende la especialización para las universidades catalanas", La Vanguardia (10 enero 2002), p. 24. Publicada luego en Departament d'Universitats, Recerca y Societat de la Informació, Generalitat de Catalunya (Colección Parlaments, n. ${ }^{\circ}$ 16, 36 pp.). Véase también su conferencia del 4 de abril de 2001 en el Museo de la Ciencia de Barcelona: «El camins europeus de Catalunya: La recerca» (en la misma Colección, n. ${ }^{\circ} 15,32$ pp.). 
MICHAVILA, Francisco: La salida del laberinto: Crítica urgente de la Universidad (Madrid: Editorial Complutense, 2001), 225 pp. Colección de 49 artículos de periódico y revista sobre la Universidad española.

MICHAVILA, Francisco, y CALVO, Benjamín: La Universidad española hoy: Propuestas para una política universitaria (Madrid: Síntesis, 1998), 318 pp. Prólogo de Josep M. Bricall.

- La Universidad española hacia Europa (Madrid: Fundación Alfonso Martín Escudero, 2000).

MIGUEL, Amando de: Diagnóstico de la Universidad (Madrid: Ediciones Guadarrama, 1973), 223 pp. Colección de artículos sobre la Universidad española.

MIGUEL, Amando de, et al.: Reformar la Universidad (Barcelona: Editorial Euros, 1976), 288 pp. Analiza el fracaso de la planificación de la enseñanza en España.

MIGUEL, Amando de, y MARSAL, Juan F.: «El raquitismo de la enseñanza de las ciencias sociales en las universidades españolas», Sistema, 24-25 (1978), pp. 89-100. Artículo seminal sobre la situación de la sociología.

MIGUEL, Jesús M. de: Anatomía de una universidad: Para un estudio de Sociología de las Organizaciones (Madrid: Dopesa, 1978), 139 pp. Número 34 de la Colección Testimonio de Actualidad. Primer estudio de sociología de las organizaciones de una universidad española (en este caso, la Universidad Autónoma de Barcelona, en Bellaterra).

- El mito de la sociedad organizada (Barcelona: Península, 1990), 171 pp. Primer premio de ensayo del País Vasco.

- «La investigación en Sociología hoy: I+D en Sociología», Revista Española de Investigaciones Sociológicas, 56 (1991), pp. 167-196.

- Estructura y cambio social en España (Madrid: Alianza, 1998), 681 pp. Ver en el índice analítico «universitaria» y «universidad».

- Recensión de Ronald G. Ehrenberg (ed.), The American University: National Treasure or Endangered Species? (Ithaca y Londres: Cornell University Press, 1997), 171 pp., en Crítica de Libros, Revista Española de Investigaciones Sociológicas, 85 (1999), pp. 324-337.

- «Reinventando la Universidad», Gestión y Análisis de Políticas Públicas, 17-18 (2000), pp. 119-157. Revisión del Informe Universidad 2000, publicado en marzo 2000 en la red.

- «De claustro a laboratorio: Cambios en la Universidad como organización del conocimiento», en María Ángeles Durán et al. (eds.), Estructura y cambio social: Libro homenaje a Salustiano del Campo (Madrid: Centro de Investigaciones Sociológicas, 2001), 1248 pp., cap. 68, pp. 1177-1205.

- La Universidad en España (Madrid: Dirección General de Universidades, Ministerio de Educación, Cultura y Deporte, 2001), $306 \mathrm{pp}$.

- «Universalizando la Universidad», Revista Española de Investigaciones Sociológicas, 93 (2001), pp. 265-276. Véanse en el mismo número las contribuciones al debate del Informe Universidad 2000, por Amparo Almarcha, Isidoro Alonso Hinojal, Miguel Beltrán, Emilio Lamo, Amando de Miguel y Juan Monreal.

- «Recensión de Víctor Pérez-Díaz y Juan C. Rodríguez, Educación superior y futuro de España (Madrid: Fundación Santillana, 2001), 470 pp., en Crítica de Libros, Revista Española de Investigaciones Sociológicas, 98 (2002).

- Anuario de calidad del sistema universitario español (Madrid: Dirección General de Universidades, Ministerio de Educación, Cultura y Deporte, 2002), 271 pp. Hay una versión corregida como Informe para la evaluación y acreditación de las universidades españolas (Barcelona: Universidad de Barcelona, 2002), 290 pp.

- Recensión de Fundación Santander Central Hispano (ed.), La Universidad en la sociedad del siglo xxI (Madrid: Fondo de Cultura Económica, 2001, 304 pp.), Revista Española de investigaciones Sociológicas, 99 (2002), pp. 254-292. 
MIGUEL, Jesús M. de: Recensión de Miguel A. Mellado et al., Documentos curso 2002/2003 (Madrid: Suplementos de El Mundo, 2002, 24 pp.), en prensa.

— Recensión de Richard S. Ruch, Higher Ed, Inc. The Rise of the For-Profit University (2003), en prensa.

— «Relación entre gasto y calidad en las universidades», Revista Española de Investigaciones Sociológicas, 99 (2002), pp. 179-188.

- Sistema de selección de profesorado para las universidades públicas españolas: Explicación para extranjeros (Madrid: Universidad de Barcelona, mimeo, 2002), 14 pp.

- ¿Sobran o faltan doctores? (Barcelona: Departamento de Sociología, Universidad de Barcelona, 2003), 33 pp., en prensa.

MIGUEL, Jesús M. de; CAIIS, Jordi, y VAQUERA, Elizabeth: «Modelo de indicadores de calidad de las universidades», Gestión y Análisis de Políticas Públicas, 16 (1999), pp. 29-62.

- Excelencia: Calidad de las universidades españolas (Madrid: Centro de Investigaciones Sociológicas, Colección Academia, 2001), 506 pp. Es el primer estudio de calidad de las universidades españolas, utilizando un centenar de indicadores. Realiza un ranking con cinco fórmulas y seis indicadores globales. El ranking final aparece en la p. 335 (tabla 4.6); ver también las tablas 4.4 y 4.5. Más información a través de demiguel@eco.ub.es.

MIGUEL, Jesús M. de; GARCÍA PONCE DE LEÓN, Omar, y ECHAVARREN, José M.: «Investigación de la investigación social», Empiria. Revista de Metodología de las Ciencias Sociales, 2 (1999).

MINISTERIO DE EDUCACIÓN Y CIENCIA: La educación en España: Bases para una política educativa (Madrid: MEC, Secretaría General Técnica, 1969), 254 pp. Conocido como el Libro Blanco. Previo a la Ley General de Educación y Financiamiento de la Reforma Educativa de 1970.

MINISTERIO DE EDUCACIÓNY CULTURA: Indicadores en la Universidad: Información y definiciones. Plan Nacional de Evaluación de la Calidad de las Universidades (Madrid: Consejo de Universidades, MEC, 1999), 491 pp. Son las actas de una reunión en la Universidad de León en junio 1999, con 38 ponencias.

MINISTERIO DE EDUCACIÓN, CULTURA Y DEPORTE: Datos y cifras: Curso escolar 2001/2002 (Madrid: MECD, 2001), $20 \mathrm{pp}$.

- La educación en la España del siglo xx (Madrid: MECD y Biblioteca Nacional, 2001), 189 pp. Es el catálogo de una exposición en la Biblioteca Nacional en septiembre-octubre 2001, para el primer centenario de la creación del Ministerio de Instrucción Pública y Bellas Artes.

- La integración del sistema universitario español en el Espacio Europeo de Enseñanza Superior: Documento-marco (Madrid: MECD, febrereo 2003), 22 pp.

MONCADA, Albert: Más allá de la educación (Madrid: Tecnos, 1983), 125 pp.

MONTORO, Ricardo: La Universidad en la España de Franco 1939-1970: Un análisis sociológico (Madrid: Centro de Investigaciones Sociológicas, 1981), $221 \mathrm{pp}$.

- «Universidad y paro: Reflexiones críticas sobre el desempleo de licenciados universitarios», Revista Española de Investigaciones Sociológicas, 24 (1983), pp. 89-111.

MORA, José G. (ed.): El profesorado universitario: Situación en España y tendencias internacionales (Madrid: Consejo de Universidades, Ministerio de Educación, Cultura y Deporte, 2000), 213 pp. Congreso en la Universidad de Burgos.

MORÁN, C.: «Un estudio sitúa a la Complutense como la mejor universidad pública», El País (25 junio 2002), p. 29. 
NIETO, Alejandro: La tribu universitaria: Fenomenología de los catedráticos de la Universidad española (Madrid: Tecnos, Status Quaestionis, 1984), 148 pp. Análisis crítico del poder de los catedráticos.

OECD: Education At a Glance (París: OCDE, 2000). Publica datos sobre la educación a todos los niveles en los países avanzados del mundo, incluyendo un cierto análisis.

OLIVER, Joseph, y RAMOS, Xavier: «Capital humano y desigualdad en España 1985-1996», Papeles de Economía Española, 88 (2001), pp. 240-256.

ORTEGA Y GASSET, José: Misión de la Universidad y otros ensayos afines (Madrid: Revista de Occidente, 1930), $185 \mathrm{pp}$. Incluye su conferencia «Sobre reforma universitaria», en el Paraninfo de la Universidad de Madrid, en 1930, 63 pp., y siete ensayos más.

PARAMIO, Ludolfo: «El Gobierno contra la Universidad», El Socialista, 642 (diciembre 2001), pp. 4-7. El número incluye también los artículos: «Una cuestión de Estado» (por Julio del Valle), «Ley de oportunidades: Una oportunidad perdida» (Carme Chacón), «La LOU no mejora la enseñanza superior» (Teresa Muñoz) y «La LOU y los usos y maneras del Partido Popular» (Fernando Lezcano).

PARÍS, Carlos: «La Universidad», en Manuel Fraga, Juan Velarde y Salustiano del Campo (eds.), La España de los años setenta: El Estado y la política (Madrid: Moneda y Crédito, 1972), pp. 509-619.

PARRADO-DÍEZ, Salvador: «Spain: Old elite or new meritocracy?», en David Farnham (ed.), Managing Academic Staff in Changing University Systems: International Trends and Comparisons (Buckingham: The Society for Research into Higher Education \& Open University Press, 1999), pp. 174-190. Incluye el estudio de diez países de la Unión Europea.

PECES-BARBA, Gregorio: «Elogio de la LRU», El País (18 septiembre 2002), pp. 15-16.

PELIKAN, Jaroslav: The Idea of the University: A Reexamination (New Haven: Yale University Press, 1992), 238 pp.

PÉREZ-DÍAZ, Víctor: «La solución universitaria», El País (4 marzo 2002), p. 16.

PÉREZ-DÍAZ, Víctor, y RODRÍGUEZ, Juan C.: Educación superior y futuro de España (Madrid: Fundación Santillana, 2001), $470 \mathrm{pp}$.

PÉREZ-DÍAZ, Víctor; RODRÍGUEZ, Juan C., y SÁNCHEZ FERRER, Leonardo: La familia española ante la educación de sus hijos (Barcelona: Fundación La Caixa, 2001), 301 pp. Es el n. 5 de la Colección Estudios Sociales.

PERKINS, James A.: The University in Transition (Princeton: Princeton University Press, 1966), 90 pp.

— (ed.): The University As an Organization (Nueva York: McGraw Hill, 1973), 273 pp.

PESCHAR, Jules L., y WAL, Marieke van der (eds.): Education Contested: Changing Relations Between State, Market, and Civil Society in Modern European Education (Exton, Pensilvania: Swets and Zeitlinger, 2000), 240 pp.

RAMÓNY CAJAL, Santiago: Reglas y consejos sobre investigación científica: Los tónicos de la voluntad (Madrid: Espasa Calpe, Colección Austral, 1991), 12. ${ }^{a}$ edición, 218 pp. El autor es Premio Nobel de Medicina en 1906, a los 54 años. El prólogo es de Severo Ochoa, el otro Premio Nobel español (1959). Es su discurso de ingreso en la Academia de Ciencias Exactas, Físicas y Naturales en diciembre de 1897. Termina aconsejando «preparar una España de porvenir que nos vengue de la España del presente» (p. 218).

«Ranking de universidades», Gaceta Universitaria, 413 (24 junio 2002), pp. 1-15.

REAL DECRETO 774/2002 (de 26 de julio), por el que se regula el sistema de habilitación nacional para el acceso a Cuerpos de Funcionarios Docentes Universitarios y el régimen de los concursos de acceso respectivos, Boletín Oficial del Estado, 188 (7 agosto 2002), pp. 29254-29268. En el anexo II incluye la lista de las 187 áreas de conocimiento, desde Álgebra a Zoología. 
ROMERO, José L., y MIGUEL, Amando de: El capital humano: Ideas para una planificación social de la enseñanza en España (Madrid: Confederación Española de Cajas de Ahorros, 1969), 263 pp. La mejor crítica del Libro Blanco y del proyecto de Ley General de Educación, con una elaboración estadística excelente.

RUCH, Richard S.: Higher Ed, Inc. The Rise of the For-Profit University (Baltimore: The Johns Hopkins University Press, 2001), 182 pp. Estudio de las empresas que realizan educación terciaria (cotizan en Bolsa).

SÁENZ DE MIERA, Antonio (ed.): Sistemas de gobierno de las universidades españolas: Situación actual y perspectivas de futuro (Madrid: Consejo de Universidades, Ministerio de Educación y Cultura, 1999), 330 pp. Es un curso realizado en la Universidad Internacional Menéndez Pelayo.

SÁNCHEZ-FERRER, Leonardo: «From bureaucratic centralism to self-regulation: The reform of higher education in Spain», West European Politics, vol. 20, n. ${ }^{\circ} 3$ (1997), pp. 164-184.

- Políticas de reforma universitaria en España 1893-1993 (Madrid: Instituto Juan March, 1997). Tesis doctoral en el Centro de Estudios Avanzados en Ciencias Sociales, Fundación Juan March.

- Informe sobre el sistema de gobierno de las universidades españolas basado en una encuesta a miembros del Consejo de Universidades y presidentes de Consejos Sociales (Santander: Universidad Internacional Menéndez Pelayo, 1999), 96 pp. Con 68 cuestionarios: de ellos, 34 rectores y 19 presidentes de Consejos Sociales.

SECRETARÍA GENERAL DEL CONSEJO DE UNIVERSIDADES: Informe sobre los resultados de la primera convocatoria del Plan Nacional de Evaluación de la Calidad de las Universidades (Madrid: Ministerio de Educación y Cultura, 1997), 56 pp. Hay una versión paralela en inglés, Report on the First Results of the National Plan for the Assessment of the Quality of Universities, por el General Secretariat, Universities Council (Madrid: Ministerio de Educación y Cultura, 1997), $56 \mathrm{pp}$.

- Borrador del Catálogo de Indicadores (Madrid: Ministerio de Educación, Cultura y Deporte, 2000), 60 pp. Publicado en el mes de noviembre de 2000, incluye la descripción teórica de 45 indicadores ideales a aplicar y varios factores estructurales (que denomina «de contexto»), pero sin incluir datos. Especifica que el catálogo de indicadores es «del sistema universitario público español». Incluye la lista de títulos oficiales.

- Listado de enseñanzas universitarias: Ordenado por titulaciones (Madrid: Ministerio de Educación, Cultura y Deporte, 2001), 144 pp. Existe un volumen paralelo, Ordenado por universidades, de $141 \mathrm{pp}$.

SEMIR, Vladimir de: «Euroescepticismo científico», El País (28 diciembre 2001), pp. Cataluña 2-3.

SEMIR, Vladimir de, et al.: «Un análisis de la política científica en España», Quark: Ciencia, Medicina, Comunicación y Cultura, 22-23 (octubre 2001 - marzo 2002), 144 pp.

SHILS, Edward: The Calling of Education: The Academic Ethic and Other Essays on Higher Education (Chicago: The University of Chicago Press, 1997), 294 pp. Es una versión de su libro clásico de 1984, junto con varios artículos sobre el tema.

SHILS, Edward, et al.: The Academic Ethic (Chicago: Chicago University Press, 1984), 104 pp. Se subtitula The Report of a Study Group of the International Council on the Future of the University.

SLAUGHTER, Sheila, y LESLIE, Larry L.: Academic Capitalism: Politics, Policies, and the Entrepreneurial University (Baltimore: The Johns Hopkins University Press, 1997), 276 pp.

SOTELO, Ignacio: «La reforma imposible», El País (11 diciembre 2001), p. 14.

TOURAINE, Alain: The Academic System in American Society (Nueva York: McGraw-Hill, 1974), 319 pp.

UNESCO: Statistical Yearbook 1999 (París: Unesco Publishing \& Bernan Press, 1999), un tomo. UNESCO publica los mejores datos internacionales sobre educación para todos los países del mundo, junto a los de la OCDE. 
UNITED NATIONS DEVELOPMENT PROGRAMME (UNDP): Human Development Report 2002: Deepening Democracy in a Fragmented World (Nueva York: UNDP y Oxford University Press, 2002), 277 pp.

UNIVERSIDAD AUTÓNOMA DE MADRID, SERVICIO DE BIBLIOTECA: Anuario estadístico de las bibliotecas universitarias y científicas españolas 2000 (Madrid: Servicio de Biblioteca de la Universidad Autónoma de Madrid y CRUE, Conferencia de Rectores de las Universidades Españolas, mayo 2001), 68 pp. Es un Documentos de Trabajo de la REBIUN Red de Bibliotecas Universitarias. Es el séptimo anuario. Son las estadísticas más fiables de libros de bibliotecas en la Universidad española. Incluyen datos para 59 universidades, con un total de 26,6 millones de libros (451.000 libros por universidad, con un personal de 82 por universidad, y un presupuesto anual de 3,3 millones de euros), además del CSIC, que tiene 1,4 millones de libros.

US NEWS: Best Graduate Schools: 2002 Edition (Washington DC: US News, 2001), 195 pp. Incluye «A directory of business, education, engineering, law, and medical schools". El ranking más reciente de las carreras graduadas en Estados Unidos. Puede verse actualizado en www.usnews.com.

UVALIC-TRUMBIC, Stamenka (ed.): Globalization and the Market in Higher Education: Quality, Accreditation, and Qualifications (Washington DC: Brookings Institution Press, 2002).

VAQUERA, Elizabeth: Mujeres en la Universidad: De disimilaridad a desigualdad (Barcelona: Universidad de Barcelona, 2002), 120 pp. Tesina de DEA (Diploma de Estudios Avanzados).

VAQUERA, Elizabeth, y MIGUEL, Jesús M. de: «Mujeres en la torre de marfil: Feminización de la universidad española», Gestión y Análisis de Políticas Públicas (2002), en prensa.

WIT, Kurt de, y VERHOEVEN, Jef C.: «The higher education policy of the European Union or against the member states?», en J. Huisman, P. Maassen y G. Neave (eds.), Higher Education and the Nation State (Oxford: Pergamon Press, 2001), cap. 7, pp. 194-250.

WORLD BANK: Income Poverty: Trends in Inequality (Washington DC: The World Bank, 2001), www.worldbank.org/ poverty/data/trends/inequal.htm. Contiene los datos de desigualdades económicas en el mundo. 
This article comprises a first investigation —in the $21^{\text {st }}$ century — into the University in Spain in comparison with post-secondary level education systems world wide. It analyses university resources and their distribution by countries. First it presents international data regarding general levels of scholing and then goes on to focus on «tertiary education» (post-secondary schooling level). Evolution over the last three decades is shown, as are the current estimates of student numbers. It analyses economic resources within the context of the inequalities existing in all countries around the world, besides the proportion of gross national product (GNP) and the cost per student. It differentiates the public from the private sector, various levels of the Administration, and the systems that provide students with economic assistance. Analysed in detail among such resources are those relating to research and development $(\mathrm{R}+\mathrm{D})$, in terms of human capital and budget alike. The article closes with a look at data regarding university libraries in the context of libraries as a whole that exist in each country. This article demonstrates the most significant differences between Spanish universities as compared with those in other countries in the European Union. The best possible data provided by UNESCO, the OECD, the World Bank, and the United Nations are used. This article forms part of a line of research that is being developed in collaboration with several centres: University of Barcelona, the State University of Navarre (these first two are located in Spain), Georgetown University, University of Pennsylvania and the Social Sciences Committee of the European Cooperation in the Field of Scientific and Technical Research (part of the European Commission in Brussels). 